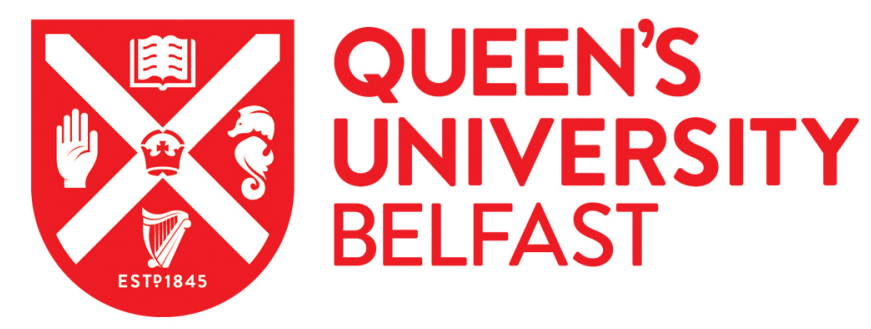

\title{
Compressive strength estimates for adiabatically cured concretes with the Modified Nurse-Saul (MNS) maturity function
}

Soutsos, M., \& Kanavaris, F. (2020). Compressive strength estimates for adiabatically cured concretes with the Modified Nurse-Saul (MNS) maturity function. Construction and Building Materials, 255, [119236].

https://doi.org/10.1016/j.conbuildmat.2020.119236

\section{Published in:}

Construction and Building Materials

\section{Document Version:}

Peer reviewed version

Queen's University Belfast - Research Portal:

Link to publication record in Queen's University Belfast Research Portal

\section{Publisher rights}

Copyright 2020 Elsevier.

This manuscript is distributed under a Creative Commons Attribution-NonCommercial-NoDerivs License

(https://creativecommons.org/licenses/by-nc-nd/4.0/), which permits distribution and reproduction for non-commercial purposes, provided the author and source are cited.

\section{General rights}

Copyright for the publications made accessible via the Queen's University Belfast Research Portal is retained by the author(s) and / or other copyright owners and it is a condition of accessing these publications that users recognise and abide by the legal requirements associated with these rights.

Take down policy

The Research Portal is Queen's institutional repository that provides access to Queen's research output. Every effort has been made to ensure that content in the Research Portal does not infringe any person's rights, or applicable UK laws. If you discover content in the Research Portal that you believe breaches copyright or violates any law, please contact openaccess@qub.ac.uk. 
1 Compressive strength estimates for adiabatically cured concretes with the Modified Nurse-Saul (MNS) maturity function.

3

4 Marios Soutsos $^{\text {a,* }}$ and Fragkoulis Kanavaris ${ }^{b}$ 5

6 a School of Natural and Built Environment, Queen's University Belfast, Belfast BT9

$7 \quad 5 \mathrm{AG}$ UK

$8 \quad$ b Formerly at Queen's University Belfast, currently at Specialist Technology \&

9 Research, ADE, Arup, London W1T 4BQ, UK (email: frag.kanavaris@arup.com)

10

$11 *$ Corresponding Author

12 Professor Marios Soutsos

13 m.soutsos@qub.ac.uk

14 Phone: $+44(0) 2890974023$

15

16

17

18

19

20

21

22

23

24

25 


\section{HIGHLIGHTS}

- The effect of high early curing temperature is to accelerate the cement hydration, i.e. it starts earlier, and thus also accelerate the early age strength development.

- These enhanced strengths cannot be accurately predicted/estimated with current maturity functions like the Nurse-Saul and Arrhenius based maturity functions.

- The Modified Nurse-Saul maturity (MNS) function has been developed to account for the above deficiencies of current maturity functions. It relies on a relationship between concrete strength and the Nurse-Saul maturity index but incorporates an "acceleration" factor and a "temperature efficiency" factor.

1 - The Modified Nurse-Saul (MNS) function has been set up as an iterative procedure using a spreadsheet and the strength estimates have been shown to be more accurate than those from other maturity functions not only for the early age but also long term strengths.

5

6

7

8

9

0




\section{ABSTRACT}

2

3 The Modified Nurse-Saul function relies on (a) a relationship between concrete

4 compressive strength and the Nurse-Saul maturity index, (b) an "acceleration" factor

5 and (c) a "temperature efficiency" factor. The "acceleration" compresses a certain

6 percentage of hydration or strength development into a smaller time interval. The

7 strength development rate is therefore increased because of the "compression" of the

8 hydration interval. Had the hydration at higher curing temperatures been as efficient in

9 contributing to the compressive strength as at lower temperatures then the

10 "acceleration" factor would be equal to the "compression" factor. Procedures are

11 described to determine these factors from isothermally cured concretes. They are then

12 used in an iterative procedure to predict/estimate the strength development for

13 adiabatically cured concretes. The predictions/estimates are shown to be significantly

14 more accurate than those from the Nurse-Saul and Arrhenius maturity functions.

15

16 KEYWORDS

17 Curing Temperature, Compressive Strength, Maturity Function, Activation Energy 


\section{INTRODUCTION}

2

3 Two alternative functions for computing the maturity index from the measured

4 temperature history of the concrete are described in ASTM C1074-11 Standard Practice

5 for Estimating Concrete Strength by the Maturity Method [1]. The first is what has

6 become known as the Nurse-Saul function [2,3] and the second was proposed by

$7 \quad$ Freiesleben Hansen and Pedersen [4].

8

9 The Nurse-Saul function [2,3] computes the temperature-time factor as follows:

$$
M(t)=\sum_{0}^{t}\left(T-T_{0}\right) \Delta t
$$

Equation 1

11 where: $\quad M(t)$ the temperature-time factor (the maturity index) at age t,

$T_{0} \quad$ datum temperature, taken as $-11^{\circ} \mathrm{C}$ in this work.

18 Freiesleben Hansen and Pedersen's expression for equivalent age [4] is based on the

19 Arrhenius equation and it is therefore referred to as the Arrhenius maturity function in 20 this paper:

$$
t_{e}=\sum_{0}^{t} e^{-Q\left[\frac{1}{273+T}-\frac{1}{273+T_{r}}\right]} \Delta t
$$

\section{Equation 2}

where:

te $=$

equivalent age at a specified or "reference" temperature, days or hours interval $\Delta \mathrm{t},{ }^{\circ} \mathrm{C}$, 
7 The Arrhenius function appears to give, because of the use of "apparent" activation

8 energies, more accurate early age concrete compressive strength estimates than the

9 Nurse-Saul function. It has been suggested that this is because, for the Nurse-Saul

10 function, "a higher initial curing temperature results in more than a proportional

11 increase in the initial rate of hydration [14] and therefore at the same early age maturity

12 the strength of concrete cured at a high temperature is greater than that of concrete cured

13 at a lower one". Neither of the two maturity functions accounts for the detrimental effect

14 of high curing temperatures on later-age strength and thus they both overestimate the

15 later-age strengths $[8,13,15,17]$. The phenomenon of "high curing temperature resulting in a greater strength than a low curing temperature at early ages but conversely resulting in lower strength at later ages" was first reported by McIntosh in 1956 [18] and further investigated by Copeland et al. [19] and has become known as the "cross-over" effect. The long term effect is believed to occur due to the formation of dense hydrated phases around the un-hydrated cement particles, inhibiting further hydration [18,20,21]. It appears that at elevated curing temperatures, reaction products are not distributed uniformly within the pores of the hardening paste due to the coarser and porous microstructure of cement paste [20,22-24]. 
1 Functions proposed to account for the long term detrimental effect are based on a

2 decreasing apparent activation energy with increasing relative strength, degree of

3 hydration or maturity $[25,26]$. They have been reported to "give some indication of the

4 retarding effect". Whether the activation energy actually changes with degree of

5 hydration has been questioned [27] and it has been suggested that it might change as a

6 function of temperature only.

8 Recent work $[8,28]$ indicated that the detrimental effect may become apparent as early

9 as three days which is much earlier than implied by the terms "later-age" or "long-term"

10 that are usually used to describe it. This is particularly the case for when high curing

11 temperatures are applied immediately after casting, i.e. steam curing in precast works,

12 or very early age such as the adiabatic temperature rises in large concrete pours $[29,30]$.

14 Strength-time (age) and strength-maturity relationships need to be determined for the 15 particular concrete mix which can then be used in conjunction with the maturity 16 functions described above. The Three Parameter Equation (TPE) [31] is one of several 17 functions that have been proposed as strength-time (age) and strength-maturity 18 relationships:

19 Strength-time (age) relationship:

$$
S=S_{\infty} e^{-\left(\frac{\tau}{t}\right)^{a}}
$$

21 where: $\mathrm{S}=$ strength at time $\mathrm{t}, \mathrm{MPa}$,

$22 \quad \mathrm{~S}_{\infty}=$ limiting strength, MPa,

$\mathrm{t}=$ age or equivalent age of curing, hours,

$\tau=$ characteristic time constant, hours,

$\alpha=$ shape parameter. 
1 Strength-maturity relationship:

3 where: 3

$$
S=S_{\infty} e^{-\left(\frac{\tau}{M}\right)^{a}}
$$

\section{Equation 4}

$\mathrm{M}=$ temperature-time factor or maturity index, ${ }^{\circ} \mathrm{C} \cdot$ hours,

$\tau=$ characteristic time constant, ${ }^{\circ} \mathrm{C} \cdot$ hours,

Changing the value of the time constant preserves the same general shape of the curve while shifting it to the left or right [32]. Changing the value of the shape parameter alters the shape of the curve in such a way that when $\alpha$ increases then the curve has a more pronounced "S" shape. Combinations of $\tau$ (shifting of the curve to the left for higher curing temperatures) and $\alpha$ (allowing for different ultimate strengths) can be used to get a good fit of the regression curve for all curing temperatures. Whether $\alpha$ should remain constant or it should change with temperature has been queried [10]. The true potential of this equation is however in its differentiated form:

$$
\frac{d S}{d t}=\frac{a \tau^{a}\left(T-T_{0}\right)}{M^{a+1}} S_{\infty} e^{-\left(\frac{\tau}{M}\right)^{a}}
$$

Equation 5

Where $M=t\left(T-T_{0}\right)$. Combining with Equation 4:

$$
\frac{1}{S} \frac{d S}{d t}=\frac{a \tau^{a}\left(T-T_{0}\right)}{M^{a+1}}
$$

Equation 6

Differentiating Equation 4 with respect to "maturity" rather than "time" results in:

$\frac{1}{S} \frac{d S}{d M}=\frac{a \tau^{a}}{M^{a+1}}$ 
2 If Saul's principle was valid then $\frac{1}{S_{r}}\left(\frac{d S}{d M}\right)_{r}$ at the reference temperature, e.g. $20{ }^{\circ} \mathrm{C}$ used

3 here, would be equal to $\frac{1}{S} \frac{d S}{d M}$ at any other temperature, whether isothermal or not. With 4 this not being the case, operations that transform $\frac{1}{S_{r}}\left(\frac{d S}{d M}\right)_{r}$ to $\frac{1}{S} \frac{d S}{d M}$ for curing 5 temperatures other than the reference are needed. These are:

- an acceleration factor to compensate for the inherent age conversion factor in Nurse-Saul function which has been shown not to be sufficient, and,

- a temperature efficiency factor to compensate for the fact that the reaction at the higher temperatures is not as efficient as at the lower temperature [33,34].

11 Determination of acceleration and temperature efficiency factors is described for three concrete mixes with 28-day target mean compressive strengths of 37, 47 and $57 \mathrm{MPa}$.

13 How these can be programmed into a spreadsheet is also described. The procedure is 14 iterative and it can predict the detrimental effect of high early age curing temperature 15 on the ultimate/limiting compressive strength. This is demonstrated for isothermally 16 cured as well as adiabatically cured concretes.

\section{RESEARCH SIGNIFIGANCE.}

20 The early-age strength development of concretes is greatly enhanced by high curing

21 temperatures, such as those used for steam curing of precast concrete elements, or in 22 structural elements as a result of the hydration being an exothermic reaction. In order 23 for contractors to be in a position to take advantage of these enhanced strengths, e.g., 24 for increased production in precast concrete factories or for fast track construction for 
1 in-situ concrete construction, there needs to be a method to predict relatively accurately

2 the strength development for these high early age temperature curing regimes.

\section{MATERIALS AND EXPERIMENTAL PROCEDURES.}

6 The concrete mixtures investigated had target mean 28-day cube compressive strengths 7 of 37,47 and $57 \mathrm{MPa}$ and thus they are referred to as PC37, PC47 and PC57. The

8 strength classes, according to BS EN 206 [35], would be C25/30, C30/37, and C40/50,

9 respectively, if a margin of approximately 7 to $10 \mathrm{MPa}$ is allowed. "Equivalent" mortars

10 were not used in this work for determination of the "apparent" activation energies [1].

11 Mortars that have the same water-cement ratio as well as coarse aggregate-binder ratio

12 to concretes may be considered to be "equivalent" to the concretes under investigation.

13 However, previous work has shown that the strength development of the "equivalent"

14 mortars is not exactly the same as that of concretes $[8,10]$. These small differences may

15 affect the maturity estimates and thus $100 \mathrm{~mm}$ concrete cubes were used instead for this

16 work. The mixture proportions for the concretes are shown in Table 1. 
Table 1 - Concrete mix proportions.

\begin{tabular}{|c|c|c|c|}
\hline \multirow{2}{*}{ Material } & \multicolumn{3}{|c|}{ Mix ID } \\
\cline { 2 - 4 } & PC37 & PC47 & PC57 \\
\hline Portland cement $(\mathbf{P C})\left[\mathrm{kg} / \mathbf{m}^{3}\right]$ & 300 & 373 & 420 \\
\hline Gravel $\left(\mathbf{4 - 1 0 m m}\left[\mathrm{kg} / \mathbf{m}^{3}\right]\right.$ & $1107^{3}$ & $1241^{3}$ & - \\
\hline Gravel $(\mathbf{6 - 1 4 m m})\left[\mathbf{k g} / \mathbf{m}^{3}\right]$ & - & - & $800^{4}$ \\
\hline Sand $(\mathbf{0 - 4} \mathbf{~ m m})\left[\mathbf{k g} / \mathbf{m}^{3}\right]$ & $817^{1}$ & $612^{1}$ & $580^{1}$ \\
\hline Sand $(\mathbf{0 - 2} \mathbf{~ m m})\left[\mathbf{k g} / \mathbf{m}^{3}\right]$ & - & - & $300^{2}$ \\
\hline Limestone filler $\left[\mathbf{k g} / \mathbf{m}^{3}\right]$ & - & - & 120 \\
\hline Superplasticizer dosage $[\mathbf{l t r s}]$ & - & - & 3 \\
\hline Free water $\left[\mathrm{kg} / \mathbf{m}^{3}\right]$ & 180 & 190 & 195 \\
\hline Total water $\left[\mathbf{k g} / \mathbf{m}^{3}\right]$ & 206 & 204 & 215 \\
\hline Free w/b & 0.60 & 0.51 & 0.46 \\
\hline Concrete slump $[\mathbf{m m}]$ & 135 & 120 & $700 \mathrm{~mm}$ (flow) \\
\hline Compressive streng
\end{tabular}

Compressive strength at standard curing temperature [MPa]

\begin{tabular}{|c|c|c|c|}
\hline Age [days] & PC37 & PC47 & PC57 \\
\hline $\mathbf{0 . 5}$ & 2 & 8 & 11 \\
\hline $\mathbf{1}$ & 7 & 14 & 16 \\
\hline $\mathbf{2}$ & 12 & 19 & 24 \\
\hline $\mathbf{3}$ & 15 & 26 & 33 \\
\hline $\mathbf{7}$ & 24 & 37 & 42 \\
\hline $\mathbf{1 4}$ & 31 & 43 & 47 \\
\hline $\mathbf{2 8}$ & 37 & 48 & 57 \\
\hline $\mathbf{5 6}$ & - & 54 & - \\
\hline $\mathbf{9 1}$ & - & 59 & - \\
\hline $\mathbf{1 8 2}$ & - & 60 & \\
\hline $\mathbf{1}$ & &
\end{tabular}

1 - water absorption of $0-4 \mathrm{~mm}$ sand was $1.02 \%$

2 - water absorption of $0-2 \mathrm{~mm}$ sand was $1.10 \%$

3 - water absorption of $4-14 \mathrm{~mm}$ gravel was $1.85 \%$

4 - water absorption of $6-12 \mathrm{~mm}$ gravel was $1.34 \%$ 
Portland cement (CEM I 42.5N), conforming to requirements of BS EN 197-1:2011 [36], was supplied in bags by Quinn cement and had $60 \mathrm{MPa} 28$-day compressive strength (tested in accordance with BS EN 196-1:2016 [37]). Limestone filler (calcium carbonate) Eglinton GW1 - EG was only used for the flowable mix (designated as PC57) and was supplied in bags by Omya. The chemical compositions of Portland cement (PC) and limestone filler are shown in Tables 2 and 3, respectively.

Table 2: Chemical composition of $P C$

\begin{tabular}{|l|l|}
\hline Chemical constituent & $\begin{array}{l}\text { Cement }(\% \\
\text { by weight of } \\
\text { dry mass) }\end{array}$ \\
\hline $\mathrm{SiO}_{2}$ & 21.0 \\
\hline $\mathrm{Al}_{2} \mathrm{O}_{3}$ & 5.5 \\
\hline $\mathrm{Fe}_{2} \mathrm{O}_{3}$ & 3.0. \\
\hline $\mathrm{CaO}$ & 62.5 \\
\hline $\mathrm{MgO}$ & 2.25 \\
\hline $\mathrm{SO}_{3}$ & 2.6 \\
\hline Equiv. Alks $\mathrm{Na}_{2} \mathrm{O}_{\mathrm{e}}$ & 0.525 \\
\hline Chloride & 0.045 \\
\hline Loss of ignition & 2.0 \\
\hline & \\
\hline
\end{tabular}

11

Table 3: Chemical composition of limestone filler

\begin{tabular}{|l|l|}
\hline Chemical constituent & Limestone filler \\
\hline $\mathrm{SiO}_{2}$ & $\begin{array}{l}4.3 \% \\
\text { by weight of dry mass }\end{array}$ \\
\hline $\mathrm{Fe}_{2} \mathrm{O}_{3}$ & $\begin{array}{l}0.1 \% \\
\text { by weight of dry mass }\end{array}$ \\
\hline $\mathrm{CaCO}_{3}$ & $\begin{array}{l}95.0 \% \\
\text { by weight of dry mass }\end{array}$ \\
\hline $\mathrm{Pb}$ & 1 ppm \\
\hline $\mathrm{As}$ & $0.3 \mathrm{ppm}$ \\
\hline $\mathrm{F}$ & 200 ppm \\
\hline $\mathrm{Hg}$ & $<0.01 \mathrm{ppm}$ \\
\hline $\mathrm{HCI}$ insoluble content & $\begin{array}{l}4.5 \% \\
\text { by weight of dry mass }\end{array}$ \\
\hline
\end{tabular}

The aggregates used in this study were sourced locally in Northern Ireland, supplied by the quarry of Creagh Concrete Products Ltd. The coarse aggregate used in the 37 and $47 \mathrm{MPa}$ mixes was $4 / 10 \mathrm{~mm}$ crushed basalt whilst a 6/14 mm coarse 
aggregate was used in the flowable PC57 mix. The fine aggregate used in all mixes was $0 / 4 \mathrm{~mm}$ Lough sand whilst a finer sand $(0 / 2 \mathrm{~mm})$ was also used in the flowable PC57 mix. The grading curves for the coarse and fine aggregates are shown in Fig. 1 alongside the grading limits described in BS EN 12620:2002+A1:2008 [38].

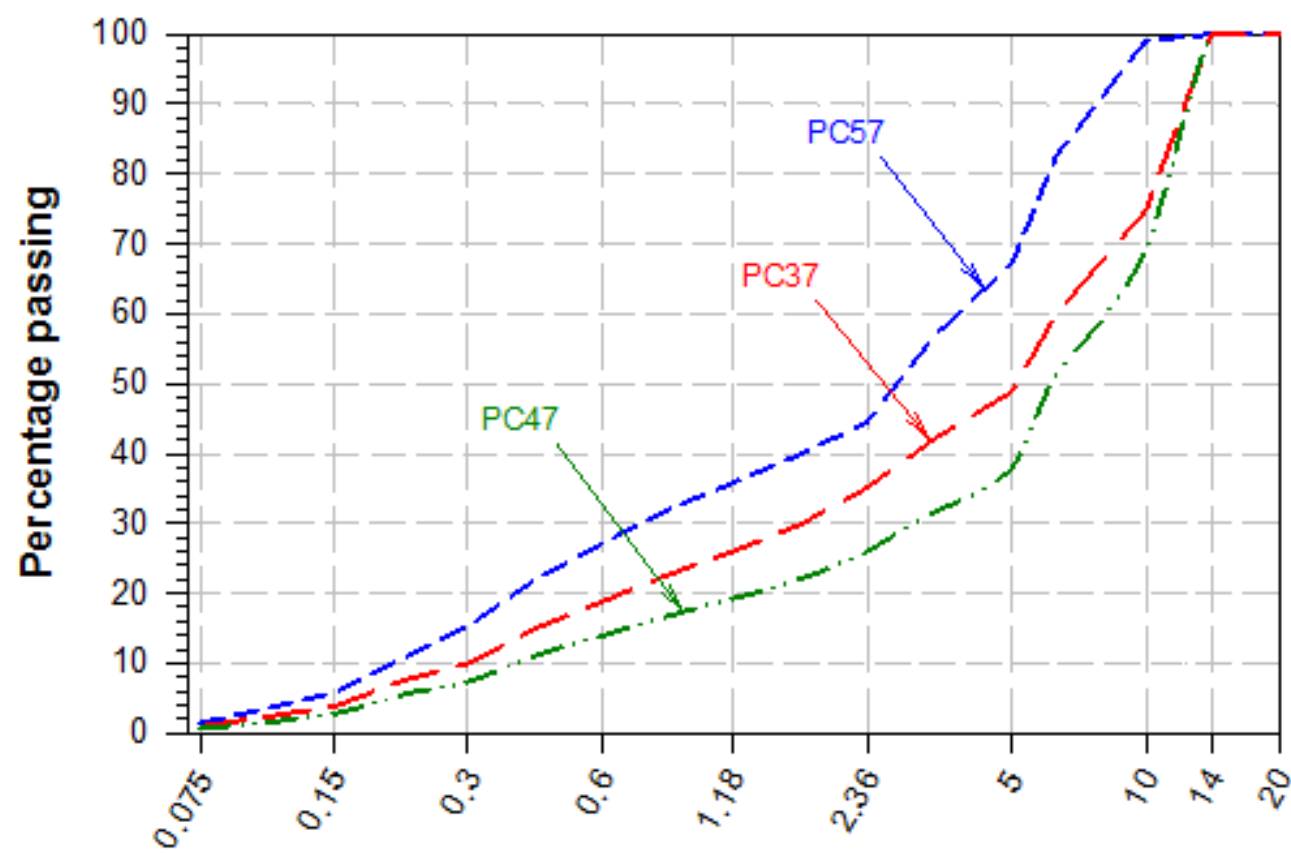

Nominal sieve size $(\mathrm{mm})$

Fig. 1: Combined aggregate grading for the investigated mixes

\subsection{Mixing, casting, curing and testing of mortar specimens}

All concrete mixes were batched using a $0.1 \mathrm{~m}^{3}$ capacity horizontal pan mixer. Aggregates, which were oven-dried for at least 24-hours, were placed first together with the cement and filler in the mixing pan. Following dry-mixing for one minute, water was added and the mixing continued for another five minutes. The workability (consistence) of concrete was determined by carrying out the slump test, in accordance with BS EN 12350-2:2009 [39]. Concrete cube (100 mm) specimens conforming to BS EN 12390-1:2012 [40] were cast in two layers and each layer was compacted using a vibrating table.

The curing procedures adopted were as follows:

- Standard curing, for which the concrete and mortar specimens inside the moulds were covered with damp hessian and polyethelene sheet and cured under 
room temperature (approximately $20^{\circ} \mathrm{C}$ ). They were subsequently demoulded at 1 day after casting and placed into a water tank set at $20{ }^{\circ} \mathrm{C}$.

- Elevated isothermal curing, for which the concrete specimens inside the moulds were wrapped using cling film and tape and were submerged in water tanks set at 30,40 and $50{ }^{\circ} \mathrm{C}$. They were demoulded at 1 day after casting (or prior to testing before that) and immediately placed back into the water tanks.

- Adiabatic curing - The adiabatic temperature rise is produced by the cement hydration and will occur if concrete is placed in a perfectly insulated environment, where there are no heat exchanges or losses, between concrete and surrounding environment. In order to achieve this in the current study, the surrounding temperature was set to be approximately the same as the concrete temperature. A $200 \times 200 \times 200 \mathrm{~mm}$ concrete cube was cast into a stainless steel box lined with $125 \mathrm{~mm}$ Rockwool $\odot$ thermal insulation and heavy duty polythene to prevent moisture loss. After casting, a stainless steel lid was bolted on top of the box and two copper/constantant thermocouples were inserted in it, through a hole in the lid, to monitor the temperature of the concrete. A PT100 probe was also inserted in the concrete through the top and was connected with the control box in order to match the temperature of the water in the tank with that of the concrete (a maximum of $-1{ }^{\circ} \mathrm{C}$ difference between water and concrete temperature was maintained). Two more thermocouples were used to monitor the temperature of the water in the tank. It was assumed that once the peak temperature had been reached and there was no temperature drop, only very little heat losses occurred and therefore, relevant adjustments to the results obtained were not required. The adiabatic curing tank and test setup are shown in Fig. 2. 


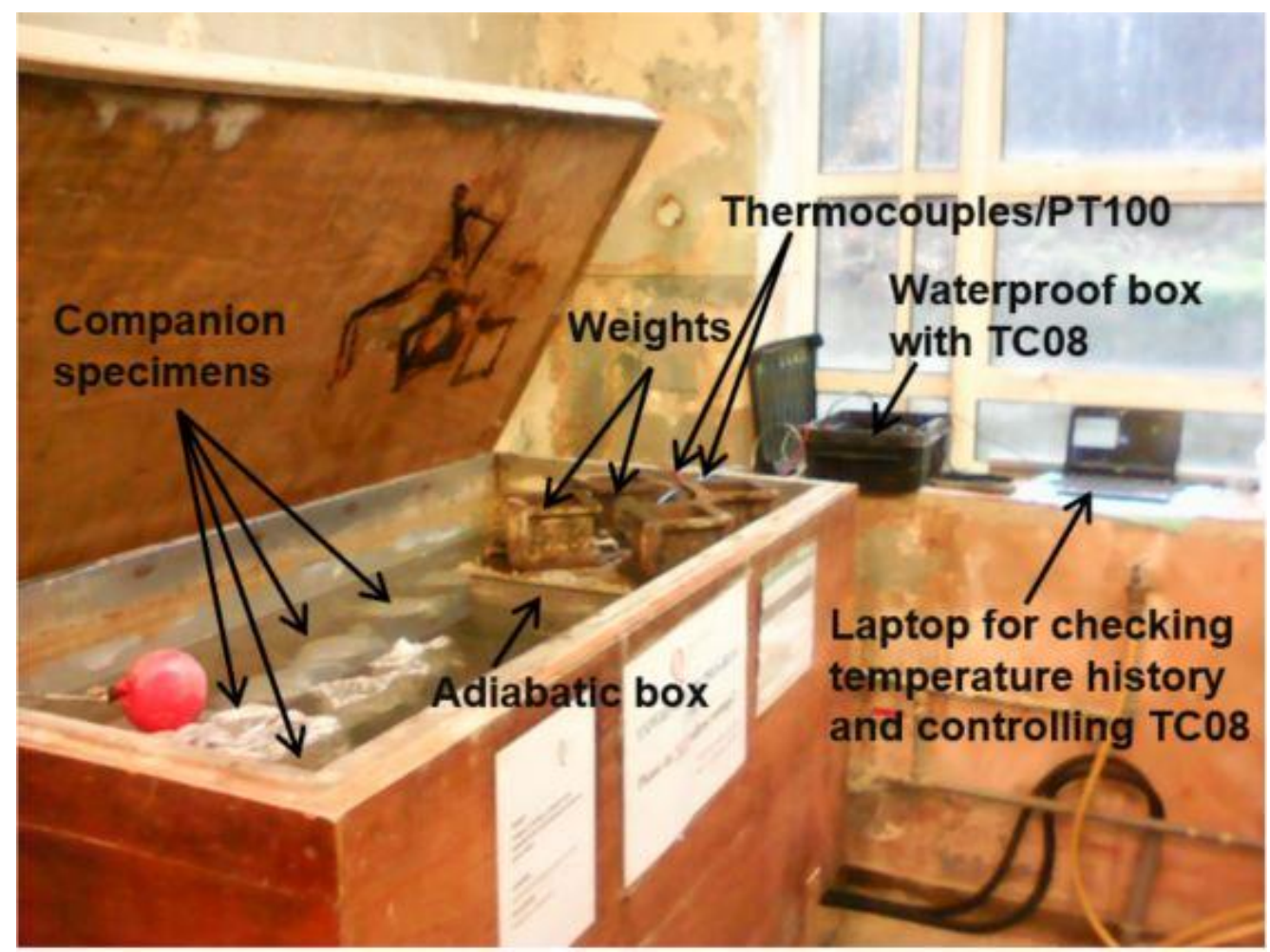

Fig. 2: Adiabatic test setup

The testing ages for all types of specimens and curing methods are shown in in Table 4. As an attempt to effectively quantify the effect of temperature on the early age compressive strength development, testing commenced as early as 3 hours $\left(50{ }^{\circ} \mathrm{C}\right), 6$ hours $\left(30,40{ }^{\circ} \mathrm{C}\right)$ and 12 hours $\left(20^{\circ} \mathrm{C}\right)$ after casting. At each testing age, 2 specimens were tested from each curing regime in term of compressive strength as described in BS EN 12390-3:2009 [41].

Table 4: Testing ages for compressive strength

\begin{tabular}{|c|c|c|c|}
\hline \multirow{2}{*}{ Curing regime } & PC37 & $\boldsymbol{P C 4 7}$ & PC57 \\
\hline \multirow{2}{*}{ Isothermal } & $\begin{array}{c}6,12 \text { hours; } 1,2,3,7,14,28, \\
56,91 \text { and } 182 \text { days }\end{array}$ & $\begin{array}{c}3,6,12 \text { hours; } 1,2,3,7, \\
14,28,56,91 \text { and } 182 \\
\text { days }\end{array}$ & $\begin{array}{c}6,12 \text { hours; } 1,2,4,8,16, \\
\text { and } 32 \text { days }\end{array}$ \\
\hline Adiabatic & $\begin{array}{c}12 \text { hours; } 1,2,3,7,14 \text { and } 28 \\
\text { days }\end{array}$ & $\begin{array}{c}12 \text { hours; } 1,2,3,7,14 \\
\text { and } 28 \text { days }\end{array}$ & $\begin{array}{c}6,12 \text { hours; } 1,2,4,8,16 \\
\text { and } 32 \text { days }\end{array}$ \\
\hline
\end{tabular}




\section{RESULTS AND DISCUSSION}

4 The data from isothermally cured specimens is first used to demonstrate the Modified

5 Nurse-Saul procedure [34] and compare the strength estimates from this with those

6 from the Nurse-Saul maturity function and the Arrhenius maturity method. Strength

7 development data from adiabatically cured concrete specimens are then used to

8 demonstrate the applicability of the procedure for non-isothermal curing regimes.

4.1 Strength estimates for isothermally cured specimens.

12 High curing temperatures result in higher early age compressive strengths, as shown in

13 Fig. 3, but later or long-term compressive strengths are adversely affected. This 14 phenomenon is what has been explained previously as the "cross-over" effect.

16 Regression curves were based on Equations 3 and 4 and the shape parameter $\alpha$ was set as 0.7 for all curing temperatures. Trial and error preceded the decision to use 0.7 which was made on the basis that it best fitted most of the results from the three mixes under investigation. No consistent relationship was found between the shape parameter $\alpha$ and curing temperature and thus its value was kept constant for all curing temperatures.

22 If Saul's principle or "maturity rule" was true then the strength development versus 23 time relationships would overlap if plotted against maturity, see Fig. 4. However, the 24 “cross-over" effect is apparent in Fig. 4 indicating that Saul's maturity rule is not valid, 25 i.e. there is no single strength-maturity relationship. At the same value of low maturity, 
1 a high curing temperature resulted in greater strength than a low curing temperature and

2 conversely at later maturities, resulted in lower strengths.

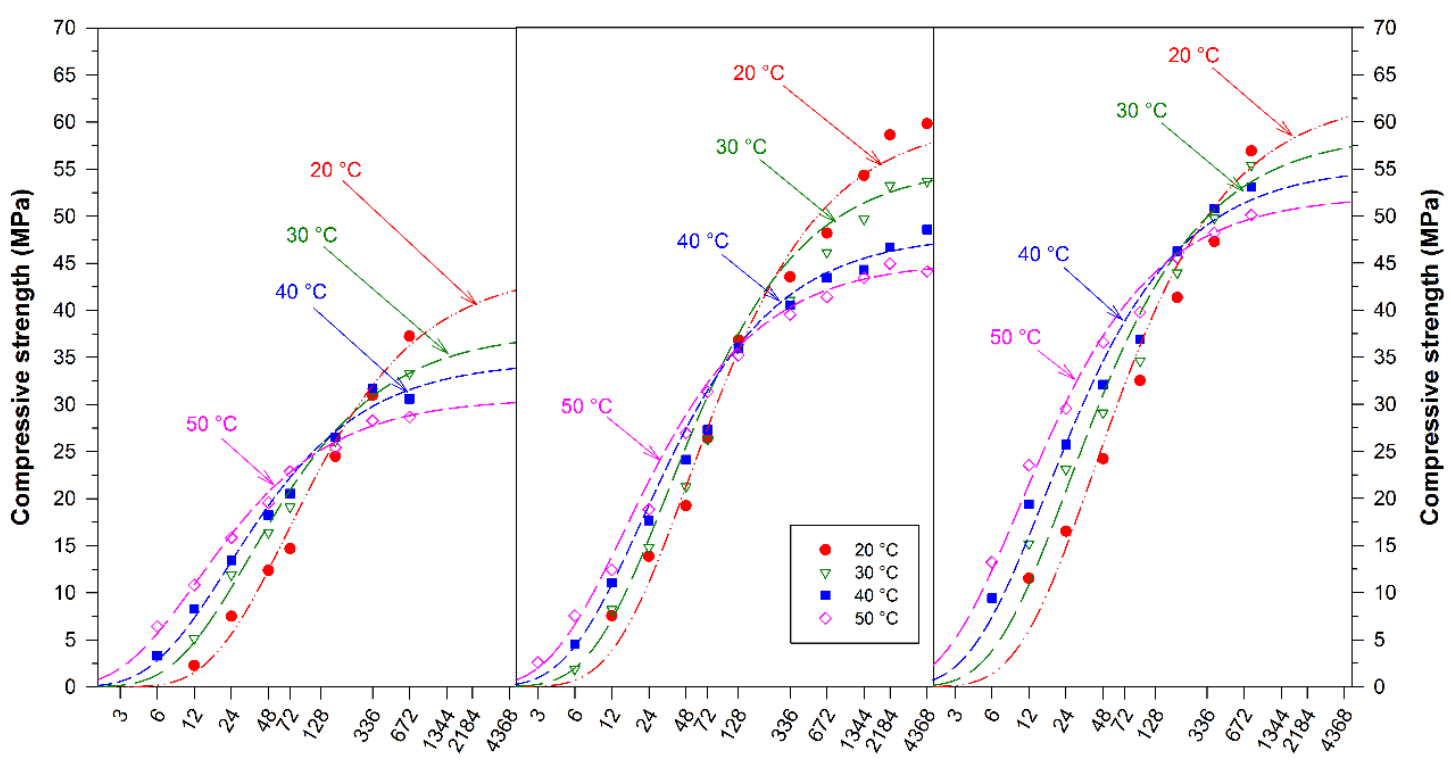

$\begin{array}{ll}\text { a) } \mathrm{PC} 37 & \text { b) } \mathrm{PC} 47\end{array}$

c) PC57

Fig. 3: Compressive strength versus age (hours) after casting.

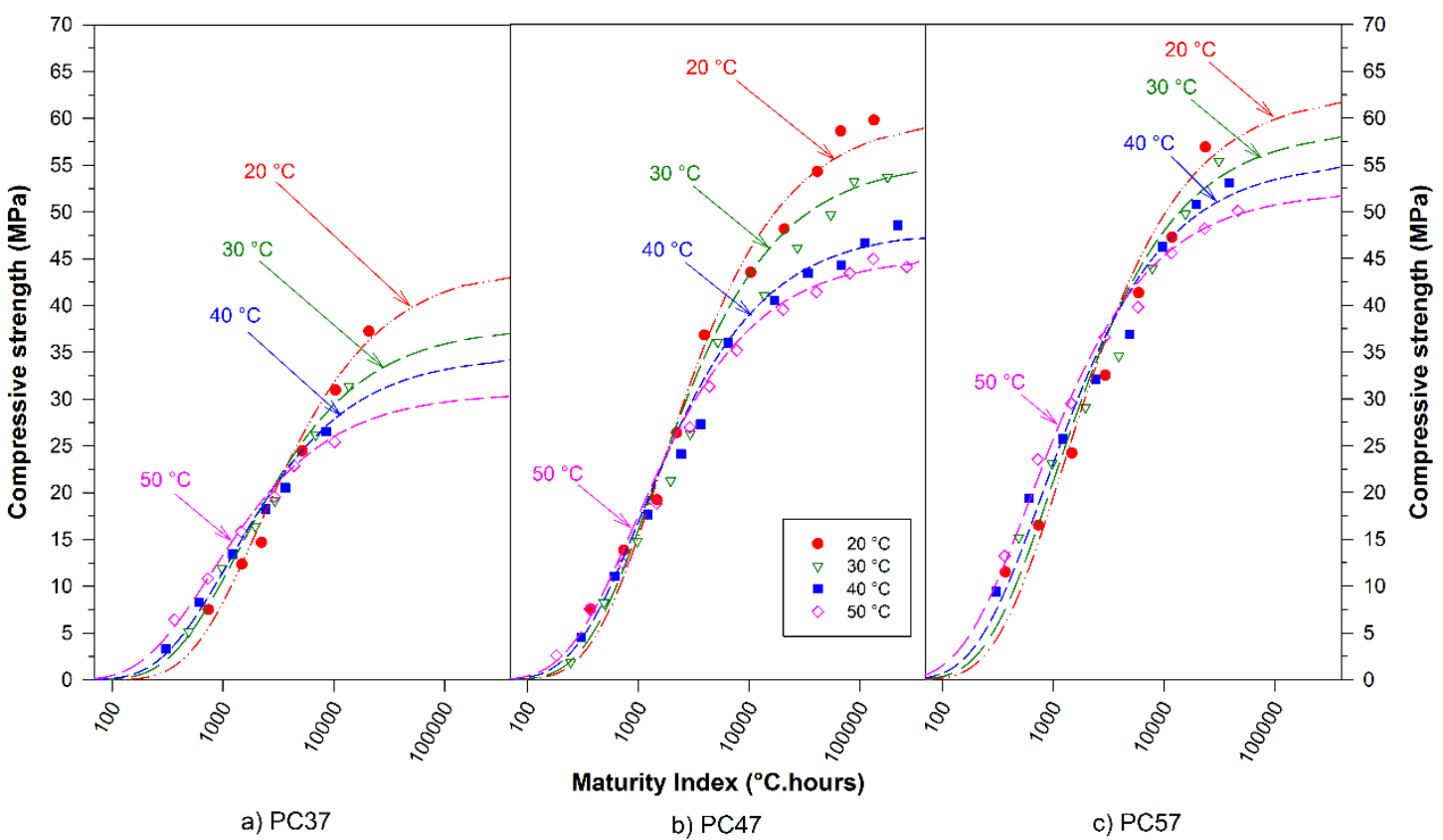

Fig. 4: Compressive strength versus maturity $\left({ }^{\circ} \mathrm{C} \cdot\right.$ hours $)$ after casting. 
1 The strength development was converted to rate of strength development with maturity

$2(\mathrm{dS} / \mathrm{dM})$ and it is shown in Fig. 5. A logarithmic scale for the maturity axis was used as

3 it accentuates differences at early maturities and thus early ages. If Saul's principle or

4 "maturity rule" were true then the rate of strength development with maturity (dS/dM)

5 should have overlapped. They do not and this is as expected since the strength

6 development versus maturity relationships did not either, see Fig 4. The maximum rates

7 of strength development, i.e. the peak of the dS/dM curves shown in Fig. 5, did not only

8 occur at earlier maturity values with higher curing temperature but they were also

9 numerically higher. The effect of temperature on the reaction was to accelerate it and

10 thus "compress" a certain maturity interval into a smaller one, e.g., the reaction up till

11 the peak for PC37 takes place at maturities of 582.8 and $219.6^{\circ} \mathrm{C} \cdot$ hours, for 20 and 50

$12{ }^{\circ} \mathrm{C}$ curing temperatures respectively (see Table 5 for values of other mixes and curing 13 temperatures).

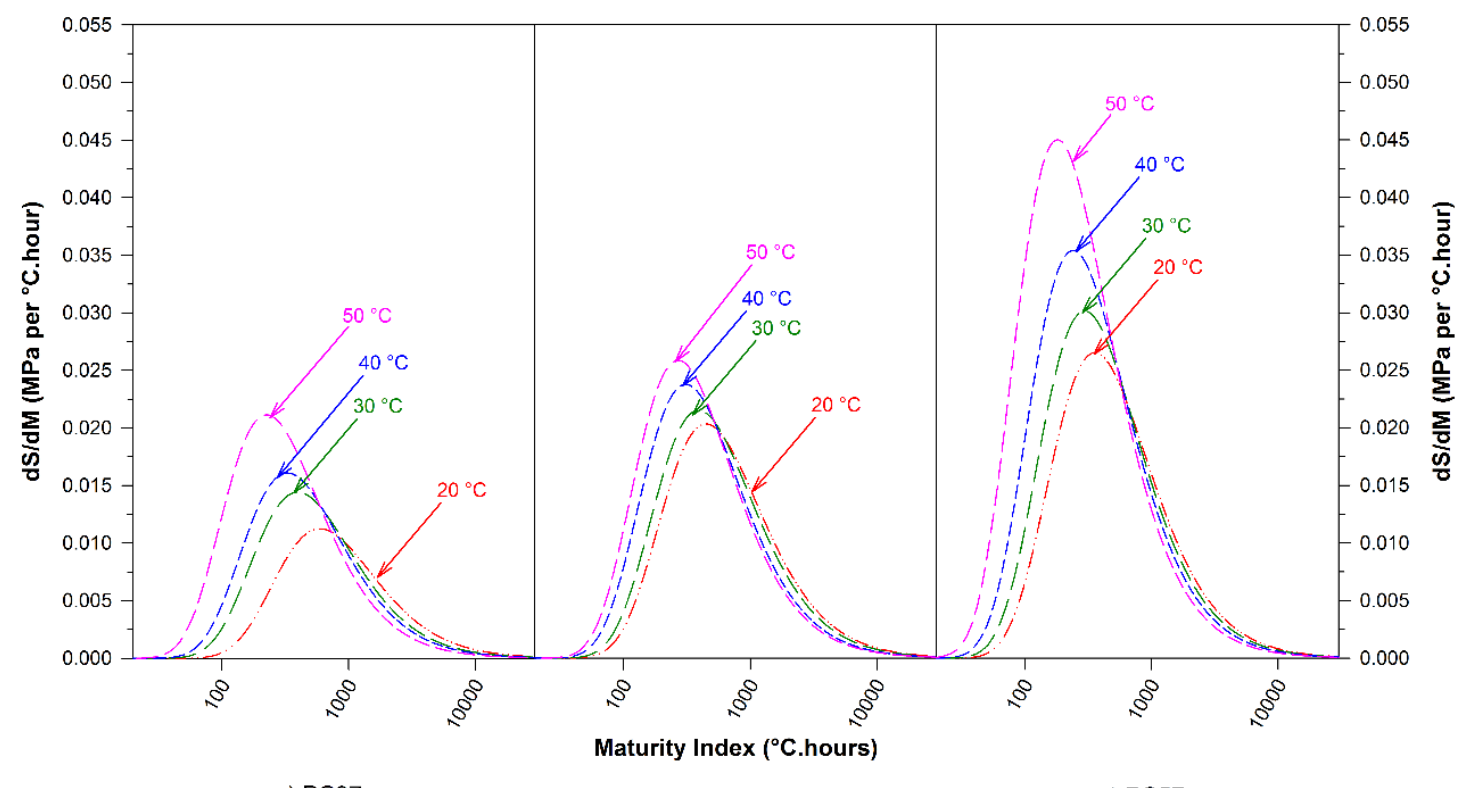
a) $\mathrm{PC} 37$

b) $\mathrm{PC} 47$ c) PC57

15 Fig. 5: Rate of compressive strength gain with respect to maturity(dS/dM) versus maturity $\left({ }^{\circ} \mathrm{C} \cdot\right.$ hours $)$ - plotted on logarithmic x-axis. 
1 Table 5: Regression constants and other parameters required for the transformation 2 of strength from the reference to other curing (isothermal and adiabatic)

3 temperatures

\begin{tabular}{|c|c|c|c|c|c|}
\hline \multirow{2}{*}{$\begin{array}{l}8 \\
3 \\
\Sigma\end{array}$} & \multirow{2}{*}{ Parameter } & \multicolumn{4}{|c|}{ Curing Temperature $\left({ }^{\circ} \mathrm{C}\right)$} \\
\hline & & 20 & 30 & 40 & 50 \\
\hline \multirow{12}{*}{$\hat{\bigcup}$} & $\mathrm{S}_{\mathrm{u}}(\mathrm{MPa})$ & 44.29 & 37.72 & 34.62 & 30.66 \\
\hline & $\tau$ (hours)* & 67.66 & 33.97 & 22.46 & 12.66 \\
\hline & $\tau\left({ }^{\circ} \mathrm{C} . \text { hours }\right)^{\#}$ & 2097.4 & 1392.8 & 1145.5 & 772.0 \\
\hline & $(\mathrm{dS} / \mathrm{dM})_{\max }\left(\mathrm{MPa}\right.$ per ${ }^{\circ} \mathrm{C}$. hour$)$ & 0.011 & 0.014 & 0.016 & 0.021 \\
\hline & M at $(\mathrm{dS} / \mathrm{dM})_{\max }\left({ }^{\circ} \mathrm{C}\right.$. hours $)$ & 582.8 & 393.6 & 323.85 & 219.6 \\
\hline & Ratio of $(\mathrm{dS} / \mathrm{dM})_{\max }$ & 1.000 & 1.264 & 1.411 & 1.853 \\
\hline & Ratio of Maturities at (dS/dM) $\max$ & 1.000 & 1.481 & 1.800 & 2.654 \\
\hline & Gradient $C_{1}$ (Ratio of Maturities) & \multicolumn{4}{|c|}{1.442} \\
\hline & Gradient $C_{2}\left(\right.$ Ratio of $\left.(d S / d M)_{\max }\right)$ & \multicolumn{4}{|c|}{0.911} \\
\hline & Acceleration factor & 1.000 & 1.497 & 2.050 & 2.654 \\
\hline & Compression factor & 1.000 & 1.290 & 1.574 & 1.853 \\
\hline & Temperature efficiency $(\%)$ & 100 & 86.2 & 76.8 & 69.8 \\
\hline \multirow{12}{*}{$\widehat{ঠ}$} & $\mathrm{~S}_{\mathrm{u}}(\mathrm{MPa})$ & 60.22 & 55.41 & 48.07 & 45.22 \\
\hline & $\tau$ (hours)* & 50.88 & 33.46 & 21.12 & 15.26 \\
\hline & $\tau\left({ }^{\circ} \text { C.hours) }\right)^{\#}$ & 1577.3 & 1371.7 & 1077.1 & 931.1 \\
\hline & $(\mathrm{dS} / \mathrm{dM})_{\max }\left(\mathrm{MPa}\right.$ per ${ }^{\circ} \mathrm{C}$. hour$)$ & 0.020 & 0.022 & 0.024 & 0.026 \\
\hline & M at $(\mathrm{dS} / \mathrm{dM})_{\max }\left({ }^{\circ} \mathrm{C}\right.$. hours $)$ & 449.5 & 387.45 & 303.45 & 262.3 \\
\hline & Ratio of $(\mathrm{dS} / \mathrm{dM})_{\max }$ & 1.000 & 1.058 & 1.169 & 1.271 \\
\hline & Ratio of Maturities at (dS/dM) $)_{\max }$ & 1.000 & 1.160 & 1.481 & 1.714 \\
\hline & Gradient $C_{1}$ (Ratio of Maturities) & \multicolumn{4}{|c|}{0.795} \\
\hline & Gradient $C_{2}\left(\right.$ Ratio of $\left.(d S / d M)_{\max }\right)$ & \multicolumn{4}{|c|}{0.355} \\
\hline & Acceleration factor & 1 & 1.249 & 1.486 & 1.713 \\
\hline & Compression factor & 1 & 1.104 & 1.193 & 1.272 \\
\hline & Temperature efficiency $(\%)$ & 100 & 88.4 & 80.3 & 74.2 \\
\hline \multirow{12}{*}{$\hat{\imath}$} & $\mathrm{S}_{\mathrm{u}}(\mathrm{MPa})$ & 62.73 & 58.79 & 55.32 & 52.18 \\
\hline & $\tau$ (hours)* & 40.63 & 25.33 & 16.32 & 10.11 \\
\hline & $\tau\left({ }^{\circ} \mathrm{C} . h o u r s\right){ }^{\#}$ & 1259.6 & 1038.5 & 832.2 & 616.8 \\
\hline & $(\mathrm{dS} / \mathrm{dM})_{\max }\left(\mathrm{MPa}\right.$ per $\left.{ }^{\circ} \mathrm{C} . h o u r\right)$ & 0.027 & 0.030 & 0.035 & 0.045 \\
\hline & $M$ at $(\mathrm{dS} / \mathrm{dM})_{\max }\left({ }^{\circ} \mathrm{C}\right.$. hours $)$ & 356.5 & 297.25 & 242.25 & 176.9 \\
\hline & Ratio of $(d S / d M)_{\max }$ & 1.000 & 1.137 & 1.335 & 1.698 \\
\hline & Ratio of Maturities at (dS/dM) $\max$ & 1.000 & 1.199 & 1.472 & 2.015 \\
\hline & Gradient $C_{1}$ (Ratio of Maturities) & \multicolumn{4}{|c|}{1.035} \\
\hline & Gradient $C_{2}\left(\right.$ Ratio of $\left.(d S / d M)_{\max }\right)$ & \multicolumn{4}{|c|}{0.782} \\
\hline & Acceleration factor & 1.000 & 1.336 & 1.674 & 2.015 \\
\hline & Compression factor & 1.000 & 1.244 & 1.476 & 1.698 \\
\hline & Temperature efficiency $(\%)$ & 100 & 93.2 & 88.2 & 84.2 \\
\hline
\end{tabular}

$4 \quad{ }^{*}$ Characteristic time constant for the strength-age relationship (Eq. 3 )

5 "Characteristic time constant for the strength-maturity relationship (Eq. 4) 
1 Taking logarithms of both sides of Equation 6 results in:

2

$$
\log \left(\frac{1}{S} \frac{d S}{d M}\right)=\log \left(a \tau^{a}\right)-(a+1) \log (M)
$$

Equation 8

3

4 indicating that the plots should be straight lines with a gradient of $-(\alpha+1)$, which

5 therefore is minus 1.7, as shown in Fig. 6 , since the shape parameter " $\alpha$ " used for the lines in Fig. 6 would have overlapped had Saul's maturity rule been valid.

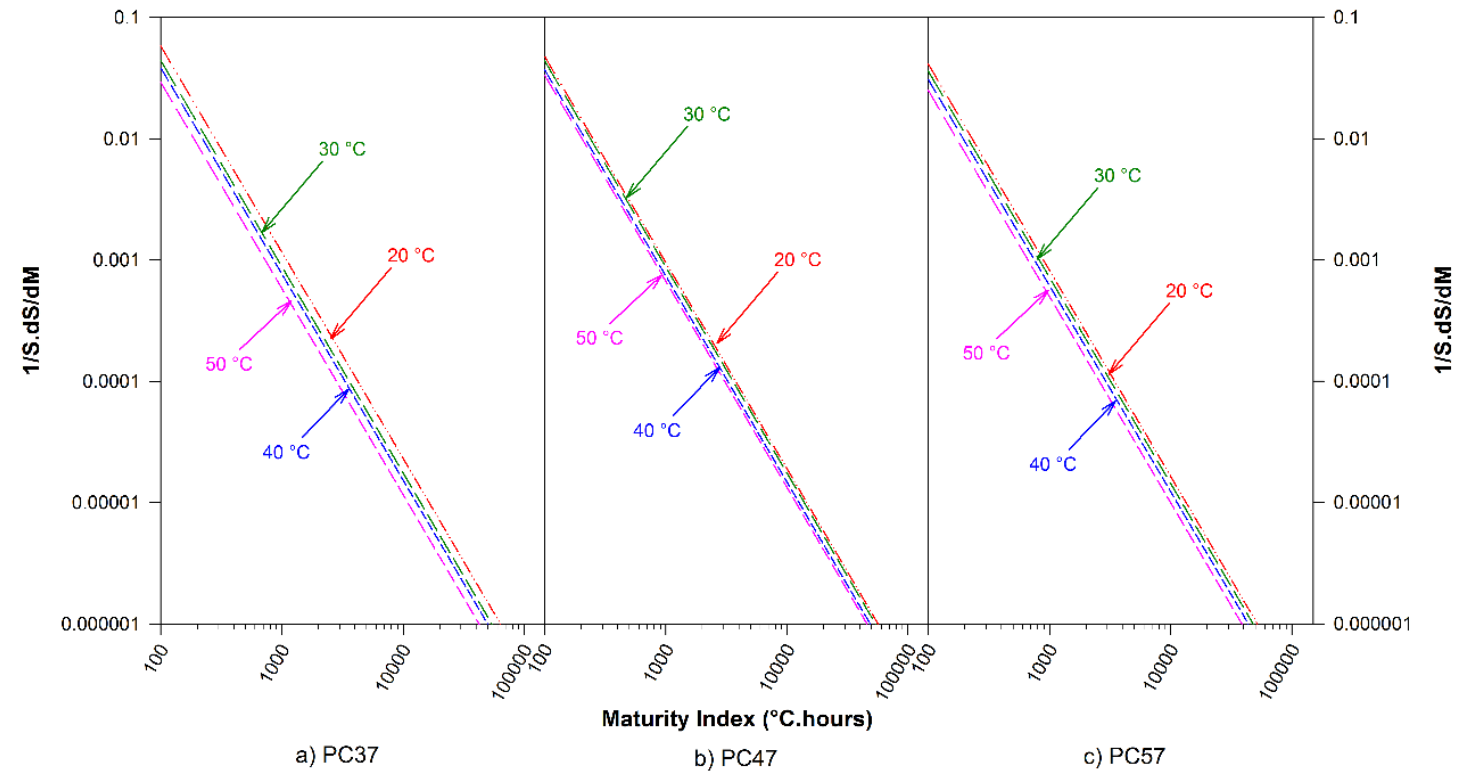

Fig. 6: Relationship of $1 / S . d S / d M$ with maturity for curing at different temperatures.

11 The rate of the reaction (in terms of maturity index rather than time) is plotted against 12 maturity in Fig. 7 for curing temperatures of 20 and $50^{\circ} \mathrm{C}$. The two rate of hydration 13 reaction curves do not coincide. An "acceleration" factor, in addition to the inherent 14 age conversion factor in the Nurse-Saul maturity function, is therefore needed 15 


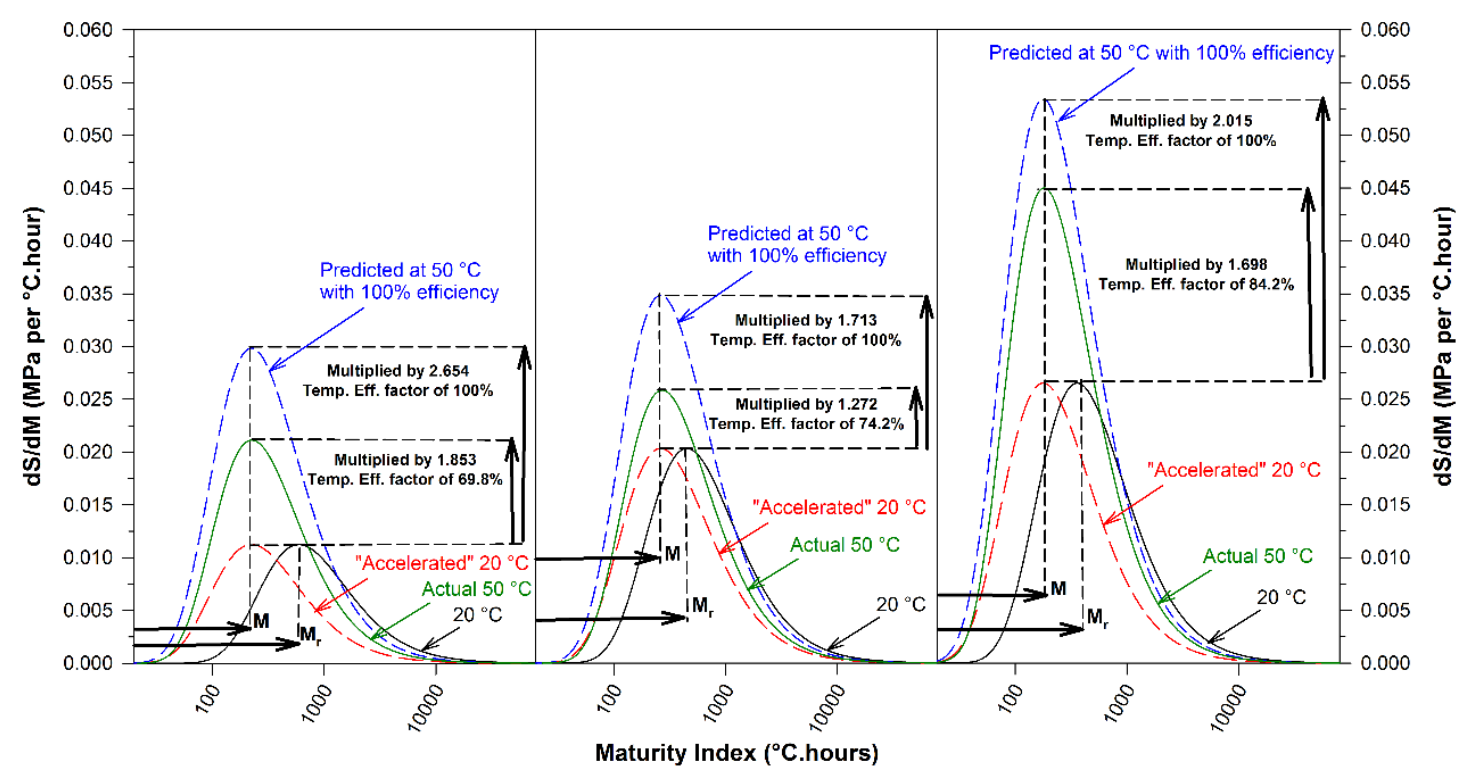
a) $\mathrm{PC} 37$

b) $\mathrm{PC} 47$

c) PC57

2 Fig. 7: "Acceleration" and "temperature efficiency" factors used to transform the 20

5 so that the $20^{\circ} \mathrm{C}$ strength-maturity relationship can be applied for curing at $50{ }^{\circ} \mathrm{C}$. The

6 determination of the "acceleration" factor requires first the ratio of the maturity at the

7 maximum $\mathrm{dS} / \mathrm{dM}$ at $20{ }^{\circ} \mathrm{C}$ to the maturity at the maximum $\mathrm{dS} / \mathrm{dM}$ at any other curing

8 temperature, in this case 30,40 and $50{ }^{\circ} \mathrm{C}$ :

$$
\text { Ratio of Maturities at }\left(\frac{d S}{d M}\right)_{\max }=\frac{M_{r\left(20^{\circ} \mathrm{C}\right)}}{M}
$$

\section{Equation 9}

where: of $20{ }^{\circ} \mathrm{C},{ }^{\circ} \mathrm{C} \cdot$ hours, 
2 The "ratios of maturities at maximum $\mathrm{dS} / \mathrm{dM}$ " are then plotted against $(T+11) /\left(T_{20}+11\right)$

3 on a $\log -\log$ scale, as shown in Fig. 8. The gradient of the straight line $C_{l}$ can then be

4 used in the following equation so that a relationship is obtained between the

5 "acceleration" factor and the age conversion factor, i.e. the ratio $(T+11) /\left(T_{20}+11\right)$,

6 inherent in the Nurse-Saul maturity function:

7

8

Acceleration Factor $(A F)=\left(\frac{T+11}{T 20+11}\right)^{C_{1}}$

Equation 10

9

10 where:

$11 \mathrm{AF}=$ "acceleration" factor

$12 C_{1}=$ the gradient of the straight line relating the ratios

13 of maturities at peak $\mathrm{dS} / \mathrm{dM}$ and age conversion factor

14 


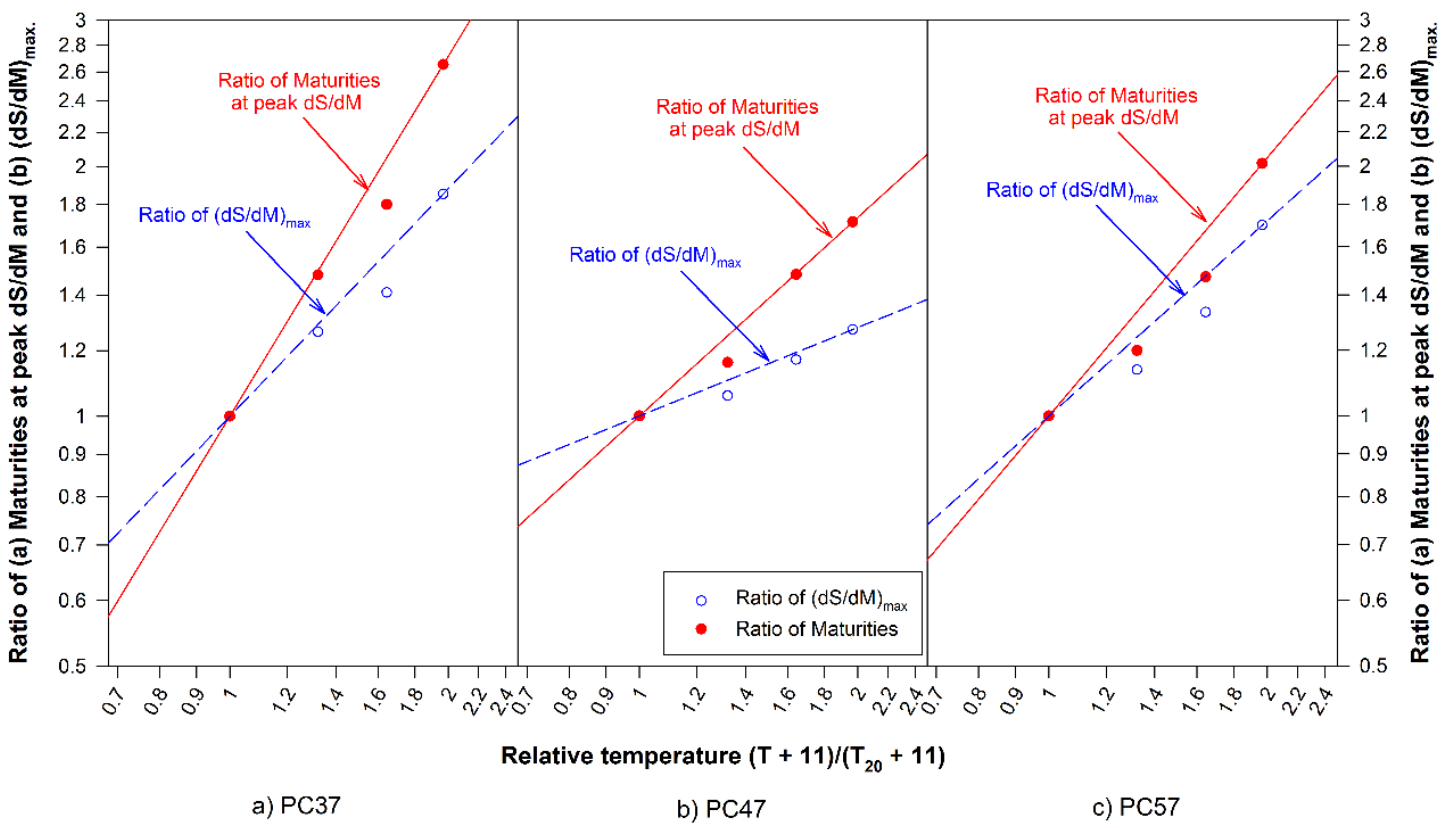

Fig. 8: Ratio of: (a) maturities at peak $d S / d M$, and, (b) $(d S / d M)_{\text {max. }}$ versus

$(T+11) /\left(T_{20}+11\right)$. 
1 The effect of this "acceleration" is to compress a certain maturity interval into a smaller

2 one. As a result of the "compression" of the hydration the numerical value of $\mathrm{dS} / \mathrm{dM}$ is

3 increased. If the reaction at the higher temperature was as efficient as at the lower

4 temperature, then the "acceleration" factor would be equal to the "compression" factor.

5 The Nurse-Saul function and indeed all other maturity functions consider that the

6 temperature efficiency is $100 \%$ irrespective of the curing temperature. The predicted

7 rates of strength development at the higher curing temperature of $50{ }^{\circ} \mathrm{C}$ and assuming

$8 \quad 100 \%$ temperature efficiency (TEF) are shown as dashed lines in Figure 7(a), (b) and

9 (c) for PC37, PC47 and PC57 respectively. It was found that these were consistently

10 higher than those obtained from regression analysis of actual strength versus maturity

11 data. The actual "compression" factor $(\mathrm{CF})$ therefore needed to be determined. The first

12 step was to determine the ratio of $\left(\frac{d S}{d M}\right)_{\max }$ for each curing temperature with that at the

13 reference temperature of $20^{\circ} \mathrm{C}$. The ratio of $\left(\frac{d S}{d M}\right)_{\max }$ is then plotted versus the age

14 conversion factor, i.e. the ratio $(T+11) /\left(T_{20}+11\right)$, on a $\log -\log$ scale as shown in Figure

15 9. The gradient of the regression line $C_{2}$ is then used to express the "compression" factor

$16(\mathrm{CF})$ as a function of the age conversion factor:

19 where:

$$
\mathrm{CF}=\text { "compression" factor }
$$
$\mathrm{dS} / \mathrm{dM}$ and age conversion factor 
1 The temperature efficiency $(\eta)$ factor is then the ratio of the

2 "compression"/“"acceleration" factors and it varies with curing temperature. As an

3 example, the temperature efficiency $(\eta)$ factor for these concrete mixes cured

4 isothermally at $50^{\circ} \mathrm{C}$, are:

5

6 a) PC37 has a Temperature efficiency factor $=\eta=1.853 / 2.654=69.81 \%$,

b) PC47 has a Temperature efficiency factor $=\eta=1.272 / 1.714=74.24 \%$,

8 and,

9

c) PC57 has a Temperature efficiency factor $=\eta=1.698 / 2.015=84.26 \%$,

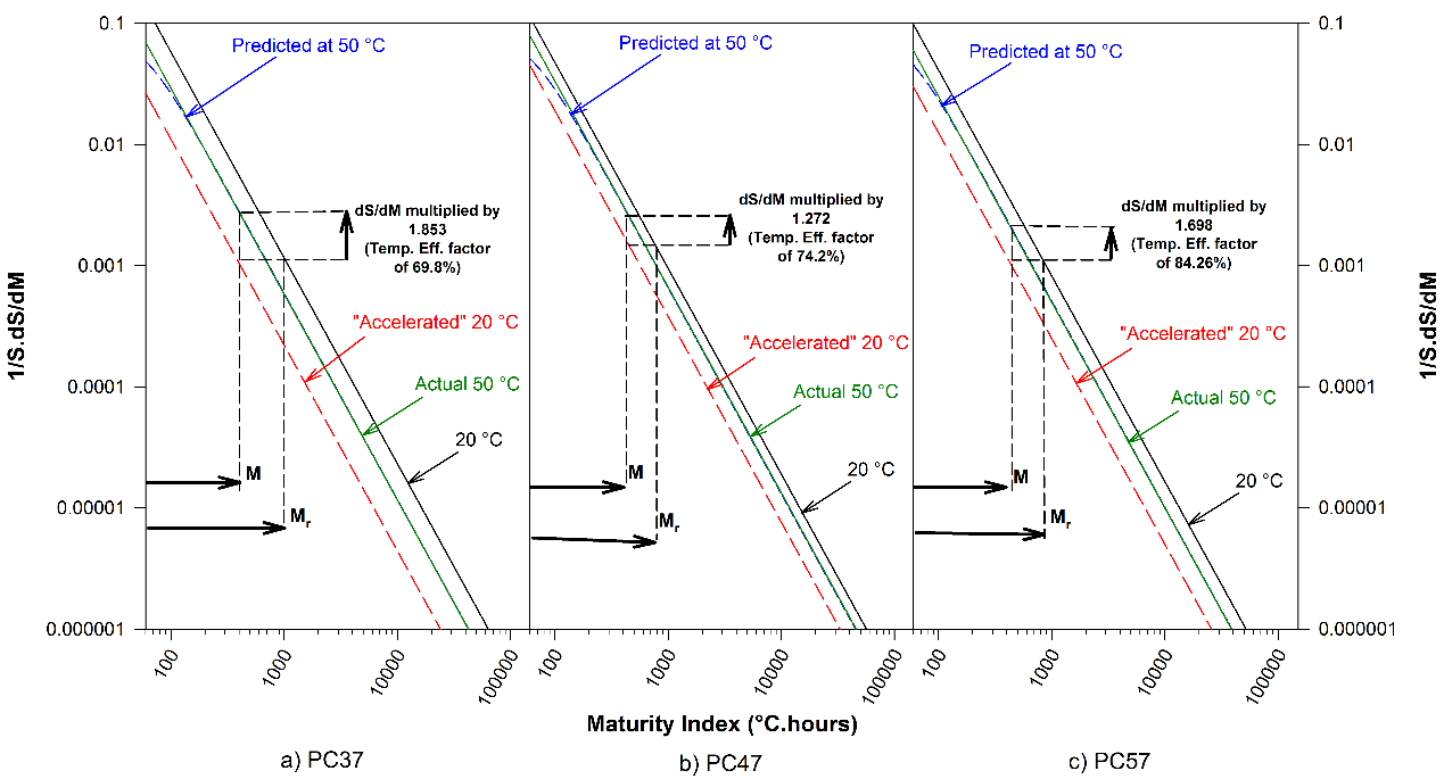

Fig. 9: "Acceleration" and "temperature efficiency" factors used to transform the 20 ${ }^{\circ} \mathrm{C}$ relationship between $1 / S . d S / d M$ and maturity to that of specimens cured at $50{ }^{\circ} \mathrm{C}$.

15 Fig. 9 shows how the relationship of the 1/S.dS/dM with maturity is first accelerated 16 and then with the use of the temperature efficiency $(\eta)$ factor is shifted upwards to 17 overlap the actual/experimentally determined relationship. If one were to plot the $100 \%$ 
1 temperature efficiency of the predicted $\mathrm{dS} / \mathrm{dM}$ at $50{ }^{\circ} \mathrm{C}$ then it would again overlap the

2 actual/experimentally determined relationship. It may at first appear surprising that

3 when the predicted $\mathrm{dS} / \mathrm{dM}$ at $50{ }^{\circ} \mathrm{C}$ and for $100 \%$ temperature efficiency for all three

4 concretes are converted to $1 / \mathrm{S} . \mathrm{dS} / \mathrm{dM}$ they again overlap the $69.81 \%, 74.24 \%$ and

$5 \quad 84.26 \%$ temperature efficiencies for PC37, PC47 and PC57 respectively and their actual

6 relationships. This is because strength and rate of strength development are interrelated,

7 see Equation 8, and they are both needed for the relationship with maturity.

9 The strength development for elevated curing temperatures and for non-isothermal 10 curing conditions can be estimated/predicted with the use of the compression factor 11 (CF) and temperature efficiency $(\eta)$ factor. An iterative procedure can be programmed in a spreadsheet; this is required in order to account for the effect of temperature on the compression factor (CF) and temperature efficiency $(\eta)$ factor at different maturities. Figure 10 shows the spreadsheet that has been developed for this purpose. The first column (A) requires the temperature history of the concretes/mortars (in this case it is 16 the adiabatic temperature history), the second (B) and third (C) is the time (in hours and days). The maturity increment is then calculated in the fourth column (D) and the maturity is shown in the fifth column (E). The "accelerated" maturity makes use of the acceleration factor (AF) previously determined. The maturity increment is multiplied by the acceleration factor (AF), calculated in column $(\mathrm{F})$, and then the maturity 21 calculated in the previous cell is added to it. The "stretch factor" is obtained by dividing 22 the "accelerated maturity" (column F) with maturity (column E). The compression 23 factor (column $\mathrm{H}$ ) is calculated from Equation 11. The temperature efficiency factor 24 (column I) is the (Compression Factor)/(Stretch Factor) ratio. Strength at the 25 accelerated maturity is then calculated in column $(\mathrm{J})$ using Equation 3 with constants 
1 for $20^{\circ} \mathrm{C}$ shown in Table 5. The maturity $\mathrm{M}$ used is the accelerated maturity in column

2 F. The accelerated $\left(\frac{1}{s} \frac{d S}{d M}\right)_{\text {accelerated }}$ is then calculated (column $\mathrm{K}$ ) based on Equation

37 noting that the accelerated maturity needs to be used:

4

5

$$
\left(\frac{1}{s} \frac{d S}{d M}\right)_{\text {accelerated }}=\frac{a \tau^{a}}{M_{\text {accelerated }}^{a+1}}
$$

Equation 12

6 The above has been calculated based on a temperature efficiency of $100 \%$ but the

7 strength increment for a certain maturity increment, i.e. $\left(\frac{d S}{d M}\right)$, is affected by both the

8 acceleration factor as well as the temperature efficiency factor $(\eta)$. Thus:

9

10

$$
\frac{1}{S_{\text {accelerated }}}\left(\frac{d S}{d M}\right)_{\text {shifted }}=\left(\frac{1}{S} \frac{d S}{d M}\right)_{\text {accelerated }} \times\left(\frac{\Delta M_{\text {accelerated }}}{\Delta M}\right) \times \text { Temp Eff }(\eta)
$$

11

Equation 13

13 The above calculation results in a shift upwards of the accelerated $\left(\frac{1}{s} \frac{d S}{d M}\right)_{\text {accelerated }}$

14 to that of the $\frac{1}{S_{\text {accelerated }}}\left(\frac{d S}{d M}\right)_{\text {shifted }}$. The shifted relationship is shown in column L.

15

16 The $\left(\frac{d S}{d M}\right)_{\text {modified }}$ is shown in column $\mathrm{M}$ and the cumulative strength, i.e. the strength 17 development, is shown in column $\mathrm{L}$. 


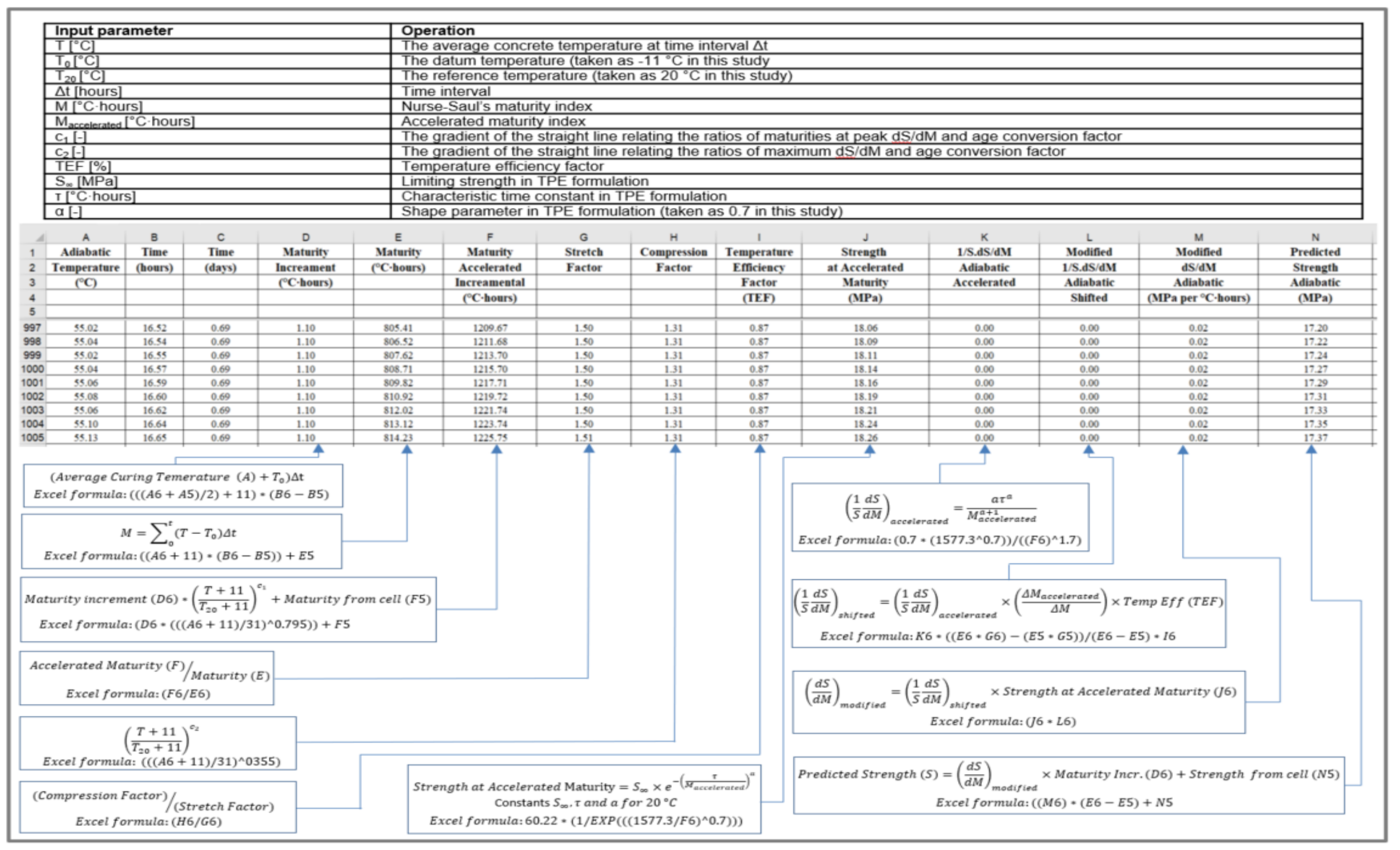

2 Fig. 10: Spreadsheet developed for the transformation of strength based on the Modified Nurse-Saul (MNS) maturity method (PC47 used as example) 
1 The $20^{\circ} \mathrm{C}$ strength development versus age relationship has been used with the above

2 procedure to estimate the strength development at curing temperatures of 30,40 and 50

$3 \quad{ }^{\circ} \mathrm{C}$ and these are shown in Fig. 11. Also shown for comparison are the strength estimates

4 for $50{ }^{\circ} \mathrm{C}$ obtained from the Nurse-Saul and Arrhenius maturity functions.

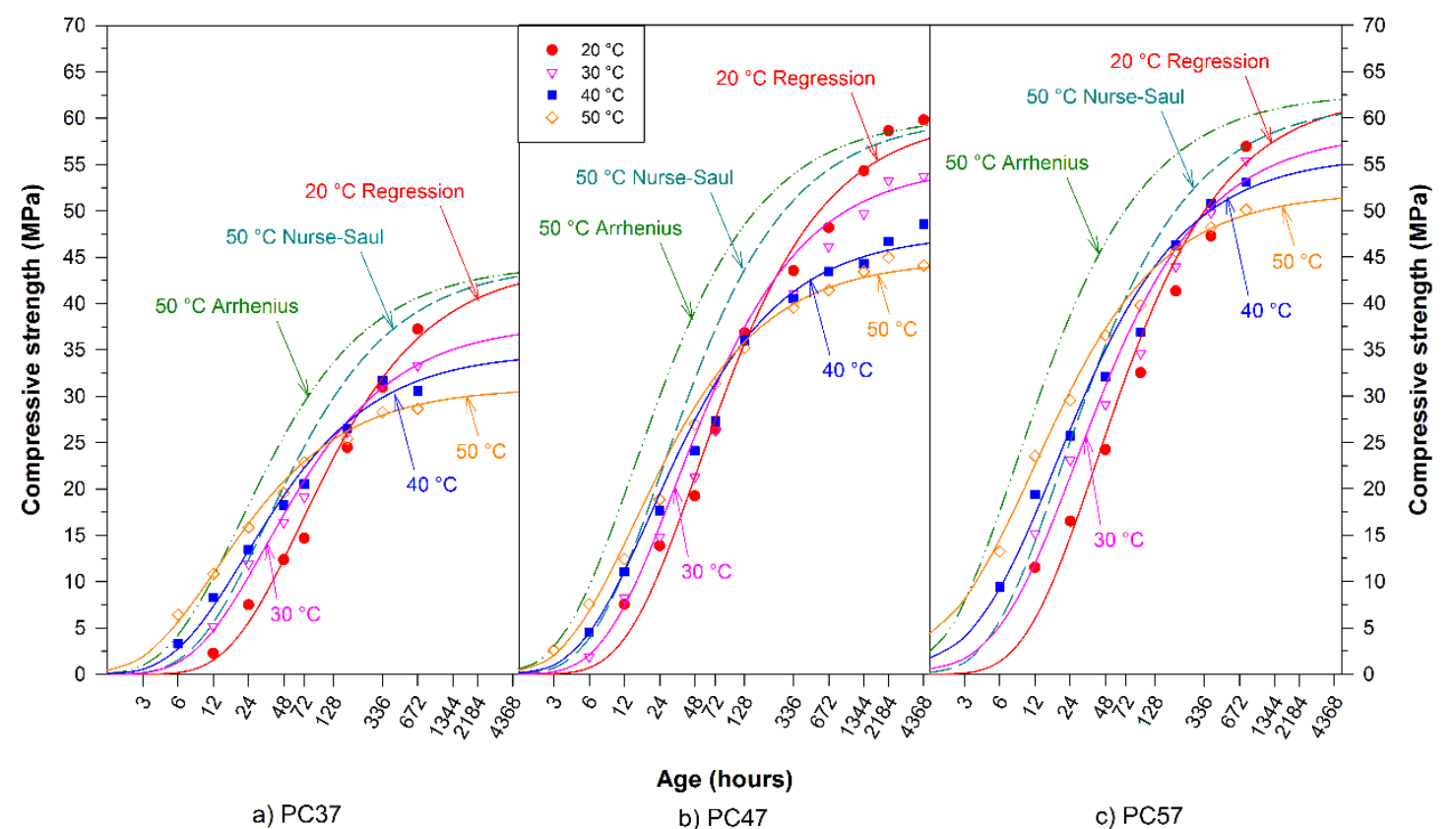

Fig. 11: Strength development estimates obtained from the Modified Nurse-Saul (MNS)

7 function. Estimates from the Nurse-Saul and Arrhenius functions for $50{ }^{\circ} \mathrm{C}$ are also

8 shown for comparison.

10 The only requirement of the Nurse-Saul function, in order to calculate the maturity

11 index according to Equation 1, is the temperature history of the concrete. Conversely,

12 in addition to the temperature history, the Arrhenius function also required the

13 "apparent" activation energies, $E_{a}$, of concretes under investigation. These were 14 previously determined [10] and they were $31.7,33.1$ and $41.1 \mathrm{~kJ} / \mathrm{mol}$ for PC37, PC47 15 and PC57, respectively. These $E_{a}$ values are in good agreement with those found in 16 other literature $[8,42-45]$. Equation 2 was used to calculate the Arrhenius equivalent 17 age $t_{e}$ at time $t$. The specified reference temperature, $T_{s}$, used was $293{ }^{\circ} \mathrm{K}\left(20{ }^{\circ} \mathrm{C}\right) . \mathrm{T}_{\mathrm{a}}$ 
1 (in ${ }^{\circ} \mathrm{K}$ ) was the average concrete temperature during time interval $\Delta t$, i.e. the recorded

2 adiabatic temperature histories. The calculated equivalent age, $t_{e}$, from Equation 2 was

3 then substituted for $t$ in Equation 3 with regression constants $S_{\infty}, \tau, \alpha$, as previously

4 determined for the strength results obtained for the concrete cured at the reference

5 temperature $\left(20^{\circ} \mathrm{C}\right)$, see Table 5 .

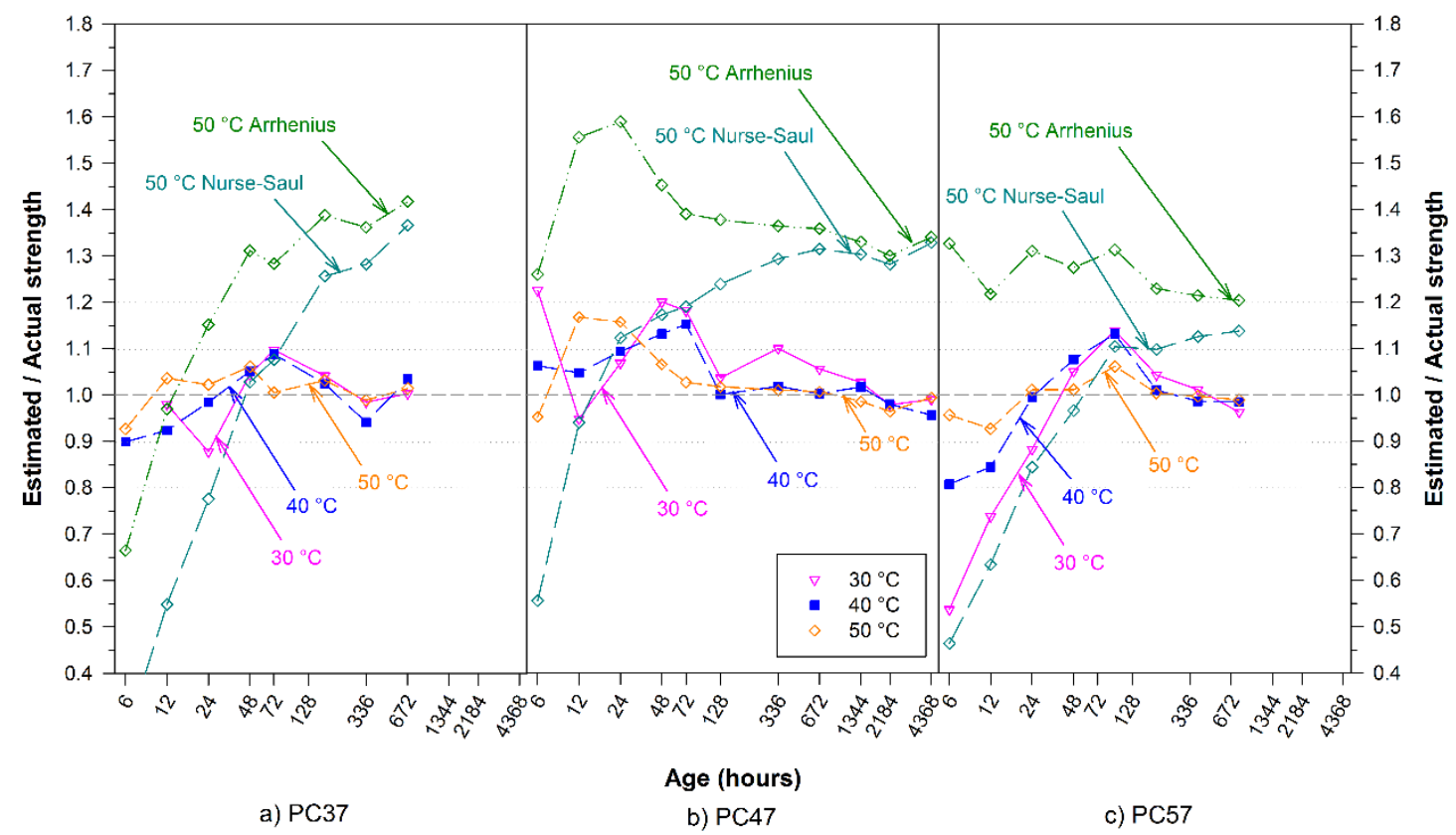

Fig. 12: Ratios of estimated/actual strengths of isothermally cured specimens using the Modified Nurse Saul (MNS) for 30, 40 and 50 C. The Nurse-Saul and Arrhenius estimates for $50^{\circ} \mathrm{C}$ are also shown for comparison. Fig. 12 uses the strength development data from Fig. 9 but converted to ratios of the estimated/actual strengths. The Modified Nurse Saul (MNS) method results in 14 compressive strength estimates that are within $\pm 20 \%$ of the actual and only rarely 15 exceed $\pm 10 \%$. The Nurse-Saul and Arrhenius methods not only under- or over16 estimated the compressive strengths at early ages but they notably overestimated the 28-day compressive strength by up to $40 \%$ in some cases. The incorporation of the 
1 detrimental effect of high early age temperatures on the long-term strengths in the

2 Modified Nurse-Saul (MNS) function resulted in not only improved early age strength

3 estimates but also improved strength estimates for later ages.

4

4.2 Strength estimates for adiabatically cured specimens.

6

7 The temperature histories of the adiabatically cured PC37, PC47 and PC57 concretes

8 are shown in Fig. 13. The PC37 having the lowest cement content of $300 \mathrm{~kg} / \mathrm{m}^{3}$ had the

9 lowest peak temperature equating to $259 \mathrm{~kJ}$ heat output per $\mathrm{kg}$ of cement. The PC57

10 seems to have reached a peak temperature much earlier than the PC47. However, the

11 PC47's temperature continued to rise beyond 40 hours after casting and exceeded that

12 of the PC57 after 67 hours since casting. The heat outputs per kg of cement were 284

$13 \mathrm{~kJ}$ and $223 \mathrm{~kJ}$ for the PC47 and PC57 respectively. It is known that heat outputs are

14 slightly reduced at lower water-cement ratios. 


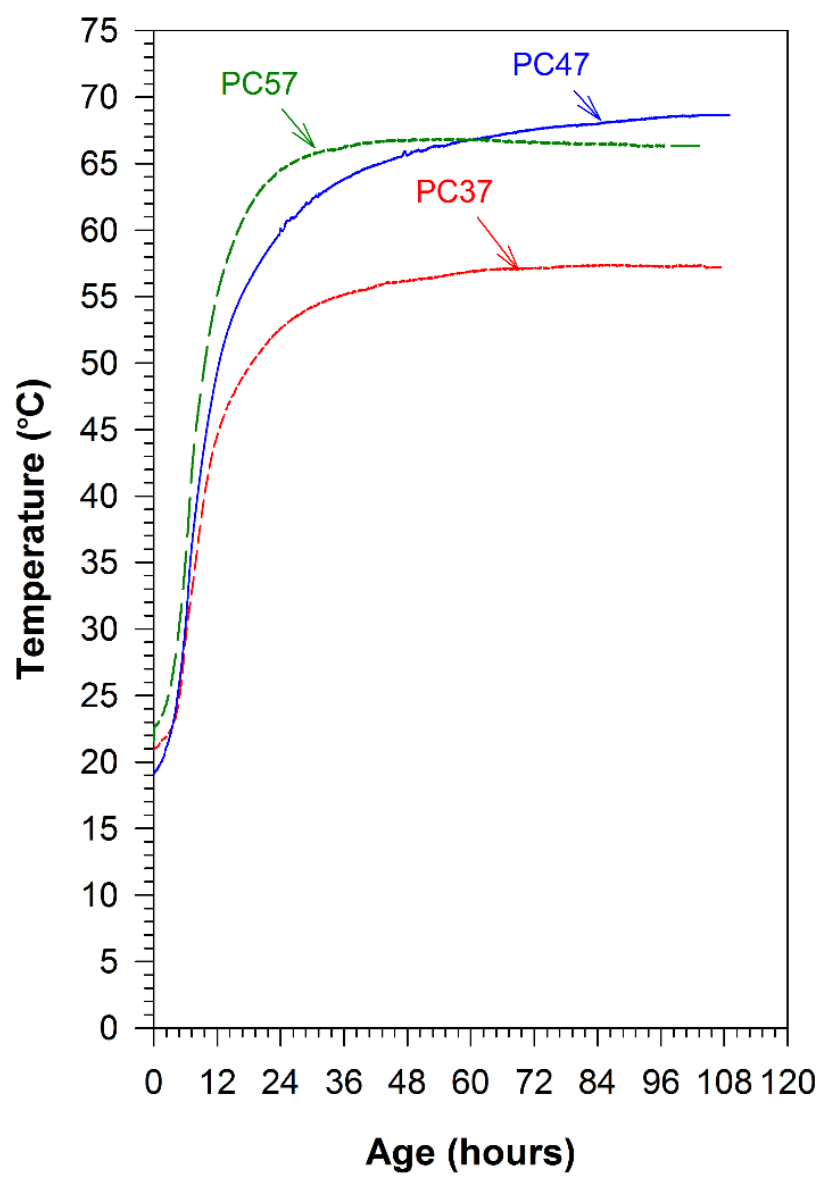

2

Fig. 13: Adiabatic temperature histories of PC37, PC47 and PC57 concretes.

4 Fig. 14 shows the strength development of these adiabatically cured specimens. High

5 curing temperatures resulted in higher early age compressive strengths but later or long-

6 term compressive strengths were adversely affected as they were for isothermally cured

7 specimens at elevated temperatures. The "cross-over" effect, previously described for

8 isothermally cured specimens, is also apparent in Fig. 14, for the adiabatically cured 9 specimens. 


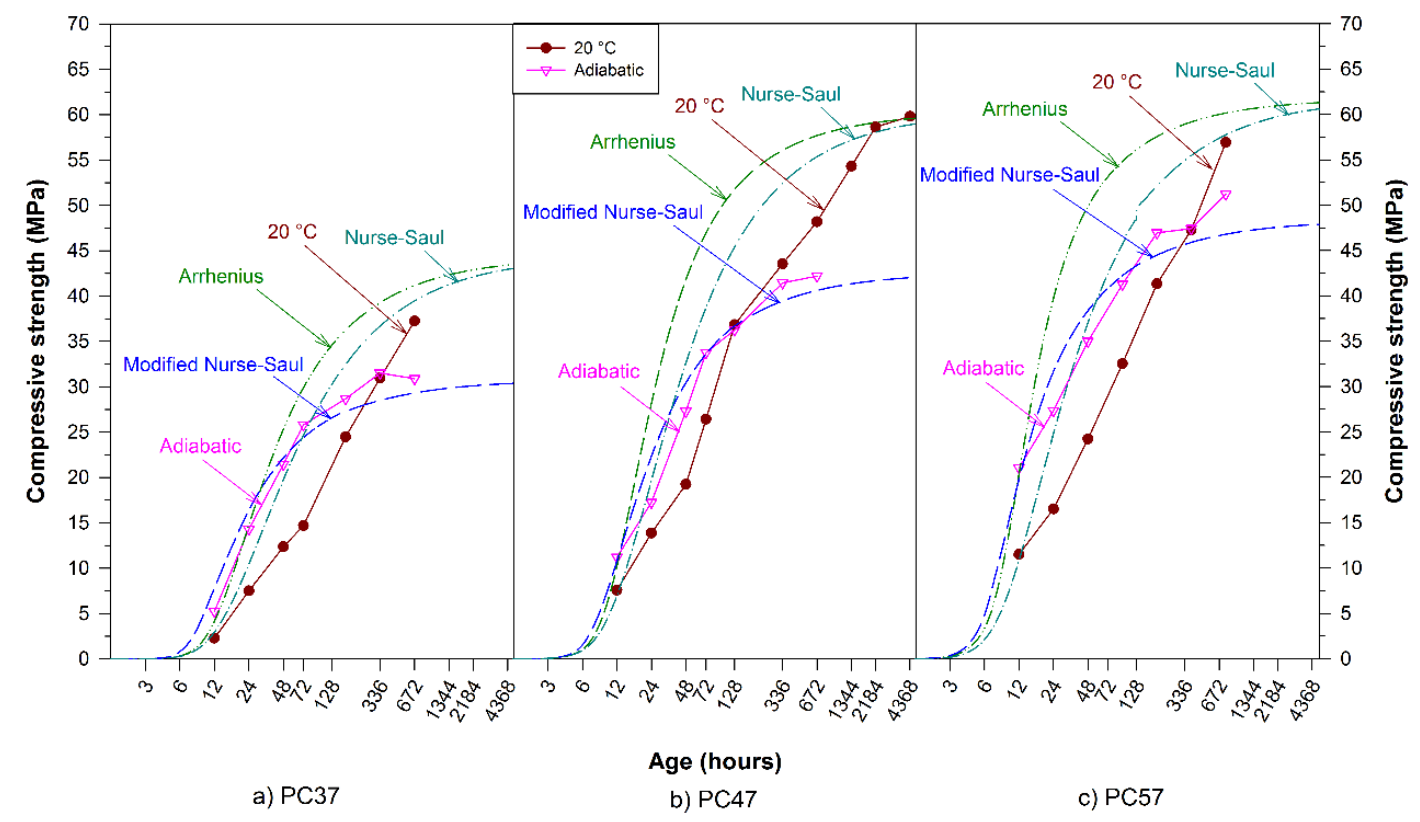

Fig. 14: Strength development of adiabatically cured specimens. Estimates obtained

3 from the Modified Nurse-Saul (MNS) function are compared to those from the Nurse-

Saul and Arrhenius functions.

6 Strength estimates for the adiabatically cured specimens were obtained from the

$7 \quad$ Modified Nurse-Saul procedure previously described and which is shown in Fig. 10 as

8 a spreadsheet. These strength estimates were used to determine the rate of compressive

9 strength gain with respect to maturity (dS/dM) which is plotted versus maturity

10 ( ${ }^{\circ} \mathrm{C} \cdot$ hours), on logarithmic $\mathrm{x}$-axis, in Fig. 15 . Also plotted is the dS/dM for 20 and 50

$11{ }^{\circ} \mathrm{C}$ for comparison purposes. The "accelerated" adiabatic dS/dM curve is shown before 12 the temperature efficiency factor $(\eta)$ is applied to it. The adiabatic $d S / d M$ is not a 13 parabola, i.e. it is not mirror-symmetrical and it is not U-shaped, as are the ones for 20 14 and $50{ }^{\circ} \mathrm{C}$. The reason for this is the non-isothermal curing temperature that results in a 15 non-constant "acceleration" factor and thus a "distorted" parabola. It is because of this 16 that it is not correct to carry out a regression analysis of the adiabatic strength 17 development curve using Equation 3; the regression "constants" do not remain constant 
1 but should vary with curing temperature. This can also be seen from Fig 16 which

2 shows the 1/S.dS/dM versus maturity relationship. The estimated 1/S.dS/dM

3 relationship is not a simple shift to the left of the $20{ }^{\circ} \mathrm{C}$ relationship; it is not even a

4 straight line! The gradient of the estimated 1/S.dS/dM relationship continuously

5 changes as does the curing temperature. This is not however because the $\alpha$ in Equation

64 changes with temperature. We have shown that the $\alpha$ remains constant with

7 temperature; what changes is the "acceleration" factor and this is what is again causing

8 the straight line to be "distorted". The line has highest gradient when the temperature

9 is changing, in this case rising, rapidly. Once the peak temperature in the adiabatic test

10 is reached then it remains almost constant and thus the gradient of the $1 / \mathrm{S} . \mathrm{dS} / \mathrm{dM}$ line

11 remains constant.

12 


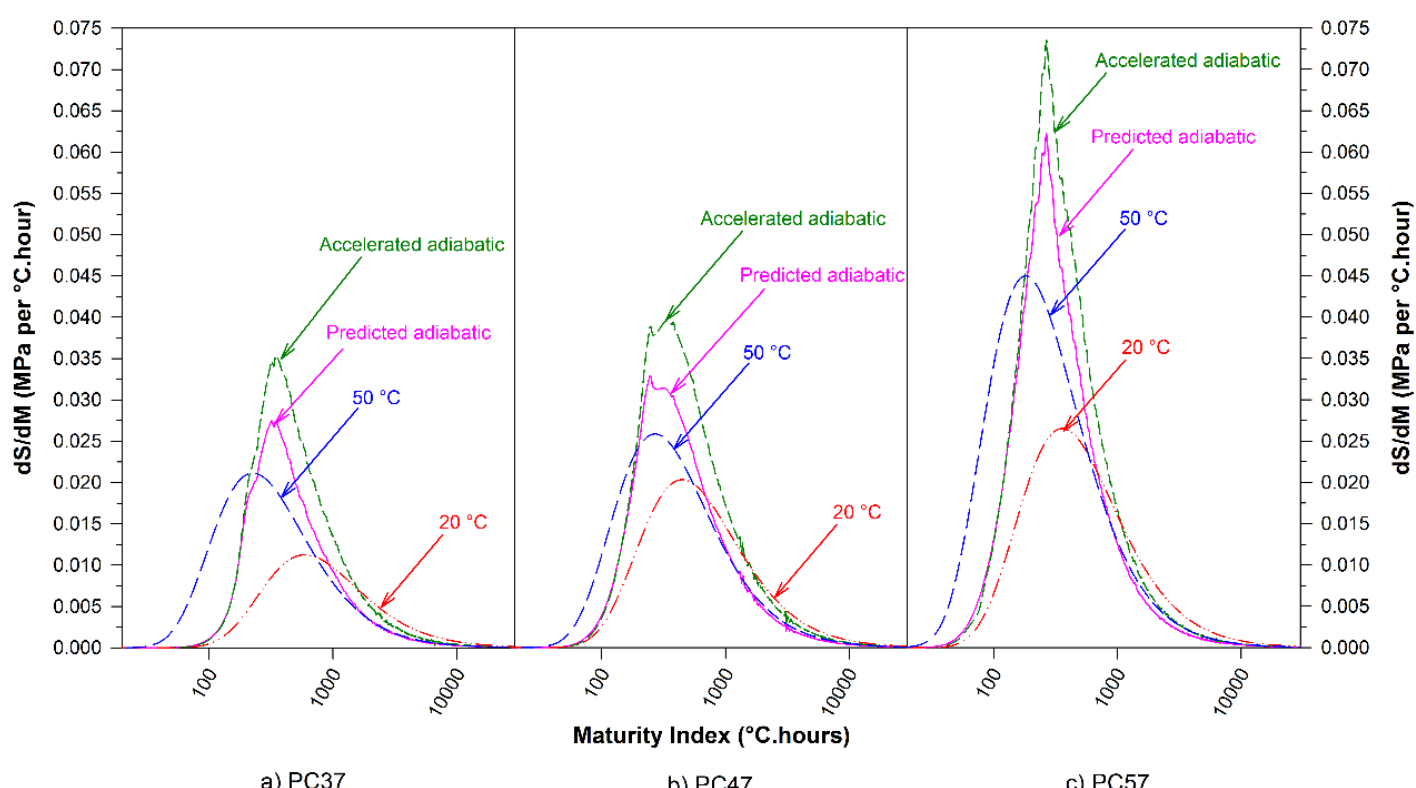

c) PC57

$2 \quad$ Fig. 15: Rate of compressive strength gain with respect to maturity(dS/dM) versus

3 maturity $\left({ }^{\circ} \mathrm{C} \cdot\right.$ hours $)$ - plotted on logarithmic $x$-axis for adiabatically cured specimens

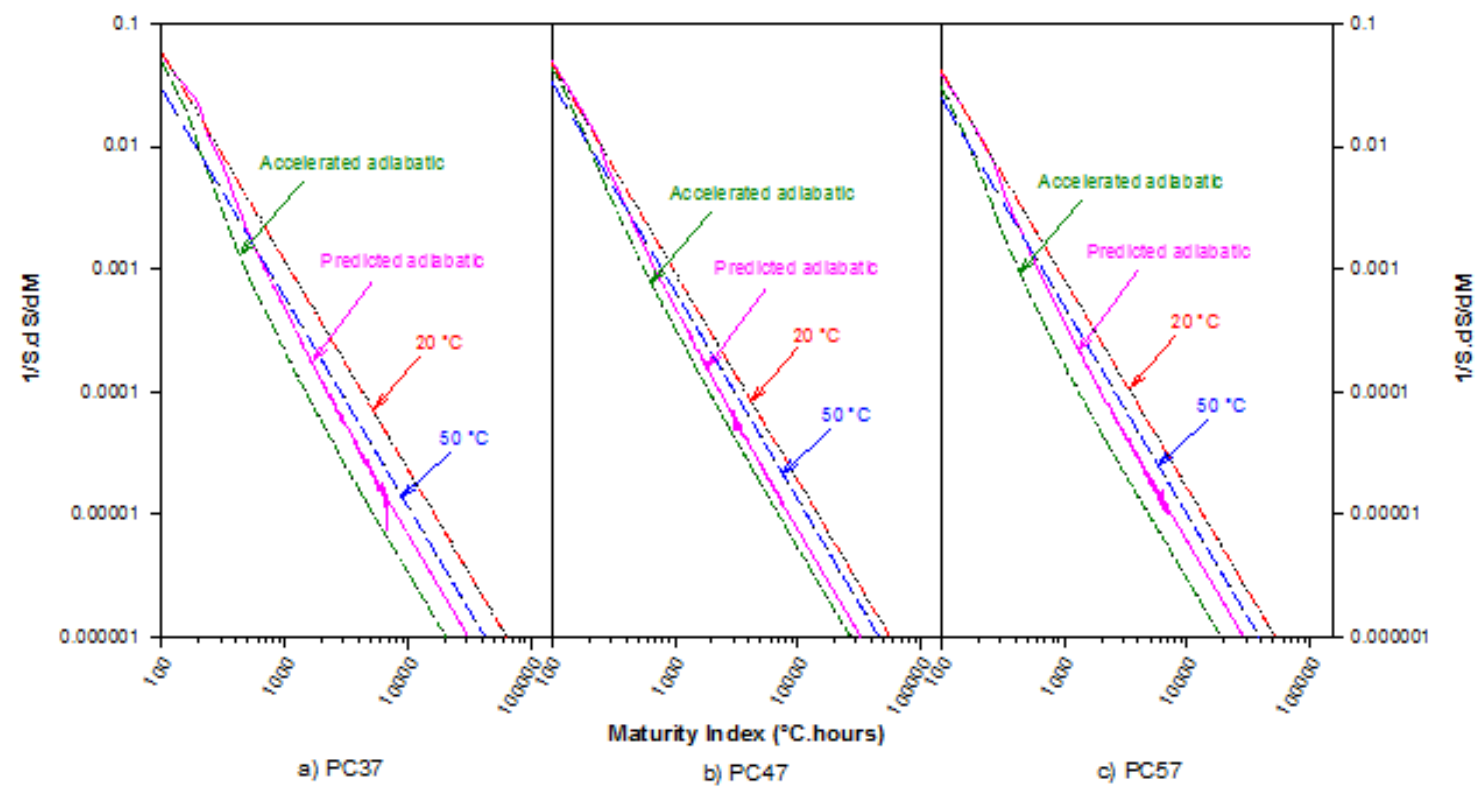

$5 \quad$ Fig. 16: Accelerated and estimated 1/S.dS/dM for adiabatic cured concrete

6 specimens. The $1 / S . d S / M$ for $50{ }^{\circ} \mathrm{C}$ curing regime is also shown for comparison 
1 The $20{ }^{\circ} \mathrm{C}$ strength development versus age relationship has been used with the

2 Modified Nurse Saul (MNS) procedure to estimate the strength development of

3 adiabatically cured specimens; in the same way as it was used for estimating the

4 strength development of isothermally cured specimens at 30,40 and $50{ }^{\circ} \mathrm{C}$. The

5 estimates from the Modified Nurse Saul (MNS) are shown in Fig. 14. Also shown for

6 comparison are the strength estimates obtained from the Nurse-Saul and Arrhenius

7 maturity functions. Fig. 17 uses the strength development data from Fig. 14 but

8 converted to ratios of the estimated/actual strengths. The Modified Nurse Saul (MNS)

9 method results in compressive strength estimates that are within $\pm 20 \%$ of the actual,

10 with the exception of PC37 at 12 hours and of PC47 at 24 hours. The estimates improve

11 to below $\pm 10 \%$ for later ages. The Nurse-Saul and Arrhenius methods not only under-

12 or over-estimate the compressive strengths at early ages but they notably overestimated

13 the 28 -day compressive strength by up to $40 \%$ in some cases. The incorporation of the

14 detrimental effect of high early age temperatures on the long-term strengths in the

15 Modified Nurse-Saul (MNS) function resulted in not only improved strength estimates

16 for later ages but also improved early age strength estimates. 


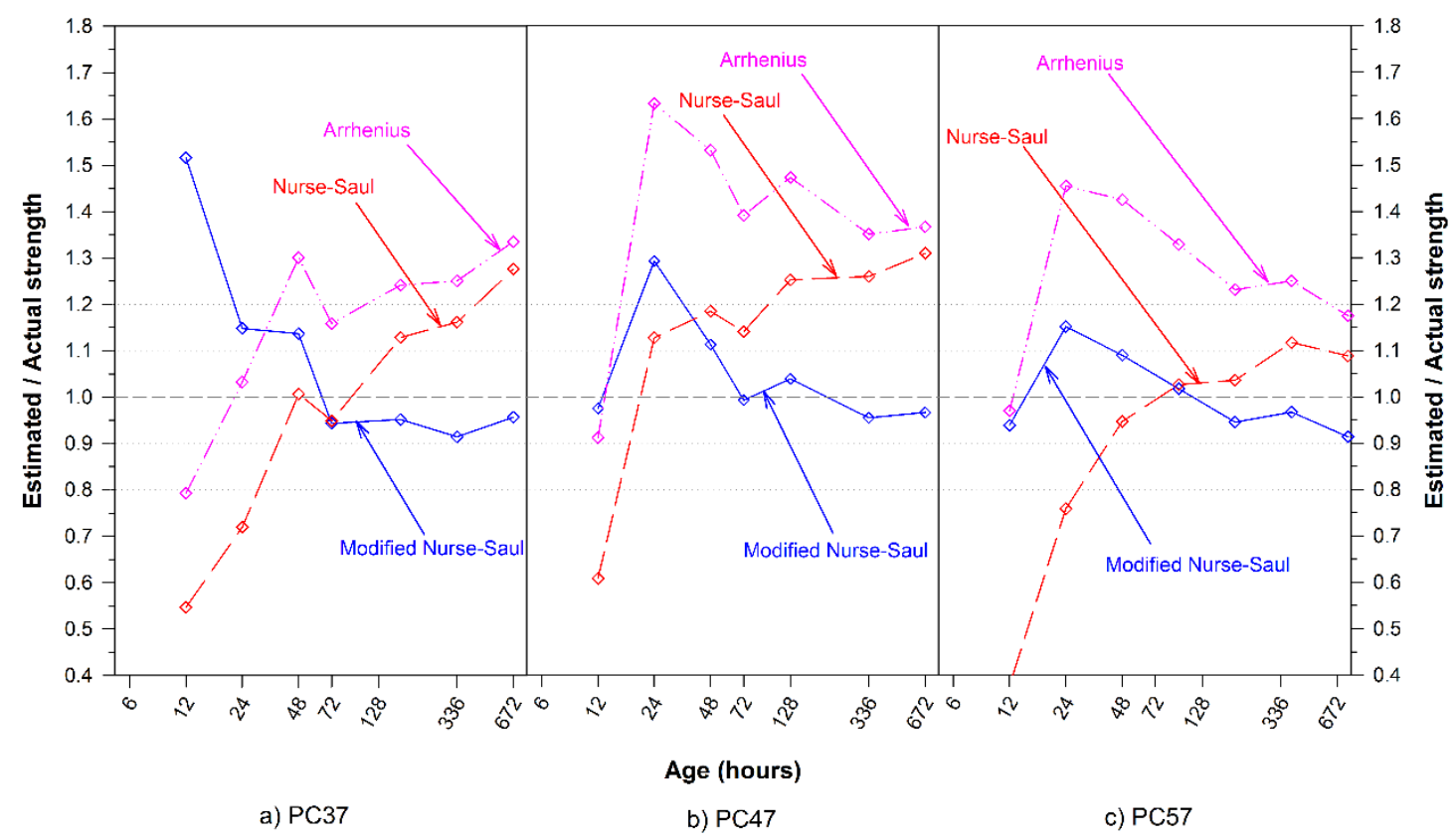

2

Fig. 17: Ratios of estimated/actual strengths of isothermally cured specimens.

4

5

6 


\section{CONCLUSIONS}

3 The effect of high early curing temperature is to accelerate the cement hydration, i.e. it

4 starts earlier, and thus also accelerate the early age strength development. It is important

5 that these strengths are accurately predicted/estimated if they will be of benefit to

6 contractors and precast concrete suppliers.

- The Nurse-Saul function appears to underestimate the concrete strength at early ages because this function assumes that the concrete strength gain rate varies linearly with temperature.

- The Arrhenius maturity function tends to over-estimate the compressive strengths especially from one day onwards because of the detrimental effect higher early age curing temperatures have on later age strengths. This detrimental effect seems to be affecting strength predictions/estimates from an earlier age than expected.

- The strength predictions/estimates from both the Nurse-Saul and Arrhenius functions converge to a single value at 28 or 32 days which was the latest testing age used for determining the strength-time relationship at $20{ }^{\circ} \mathrm{C}$. The detrimental effect of high early age curing temperatures on the long-term strengths is not accounted for.

The Modified Nurse-Saul maturity (MNS) function has been developed to account for the above deficiencies of current maturity functions. It relies on a relationship between concrete strength and the Nurse-Saul maturity index but incorporates an "acceleration" factor and a "temperature efficiency" factor.

- The "acceleration" factor can be obtained by plotting the ratio of maturities at peak $\mathrm{dS} / \mathrm{dM}$ versus the ratio of relative "temperatures + datum", i.e. $(T+11) /\left(T_{20}+11\right)$ 
- The "temperature efficiency" factor can be obtained by plotting $\mathrm{dS} / \mathrm{dM}$ at maximum values versus the ratio of relative "temperatures + datum", i.e. $(T+11) /\left(T_{20}+11\right)$.

4 The "acceleration" factor is used to modify the maturity, i.e. to accelerate it to

5 compensate for the inherent age conversion factor (which has been shown not be

6 sufficient), and this is subsequently used to determine (1/S.dS/dM $)_{\text {accelerated. This is then }}$

7 modified with the use of the "temperature efficiency" factor to compensate for the

8 reaction at the higher temperature not being as efficient as at the lower temperature. Is

9 is subsequently multiplied by the strength at the accelerated maturity to obtain the

10 strength increase over the maturity increment. The procedure is incremental in that it

11 considers the effect of temperature on the strength development over the particular 12 maturity increment considered.

14 The "acceleration" and "temperature efficiency" factors are both mixture specific and 15 they therefore need to be determined from isothermally cured specimens before they 16 can be used to predict/estimate strength development for non-isothermal curing 17 regimes, e.g., adiabatically cured concretes.

19 The Modified Nurse-Saul (MNS) function, which incorporates "acceleration" and 20 "temperature efficiency" factors, has been set up as an iterative procedure using a 21 spreadsheet and the strength estimates have been shown to be more accurate than those 22 from other maturity functions not only for the early age but also long-term strengths.

\section{ACKNOWLEDGEMENTS}


1 The development of the Modified Nurse Saul (MNS) is the work of the first author. The

2 majority of the experimental work was carried by the second author as part of his $\mathrm{PhD}$

3 research. The authors would like to thank the Department for the Economy (DfE),

4 Northern Ireland, for the postgraduate research studentship awarded to the second

5 author. The authors are very grateful to the School of Natural and Built Environment

6 (SNBE), Queen's University Belfast, for the facilities and the technical support that 7 was provided during the experimental programme of work.

\section{REFERENCES}

1. ASTM C918 / C918M-13, Standard Test Method for Measuring Early-Age Compressive Strength and Projecting Later-Age Strength, ASTM International, West Conshohocken, PA, 2013.

2. Saul, A.G.A. "Principles underlying the steam curing of concrete at atmospheric pressure," Magazine of Concrete Research, Vol. 2, No. 6, 1951, pp. 127-140.

3. Nurse, R.W. "Steam curing of concrete", Magazine of Concrete Research, Vol. 1, No. 2, 1949, pp. 79-88.

4. Freiesleben, H. P., and Pedersen, E. J. (1977) "Maturity computer for controlled curing and hardening of concrete," J. Nordic Conc. Fed, Vol. 1, pp. 21-25.

5. Soutsos, M., Hatzitheodorou, A., Kwasny, J. and Kanavaris, F. "Effect of in situ temperature on the early age strength development of concretes with supplementary cementitious materials," Construction and Building Materials, Vol. 103, 2016, pp. 105-116. 
6. Vollpracht, A., Soutsos, M. and Kanavaris, F. "Strength development of GGBS and fly ash concretes and applicability of fib model code's maturity function A critical review", Construction and Building Materials, Vol. 162, 2018, pp. 830-846.

7. Carino, N. J., and Tank, R. C. "Maturity functions for concretes made with various cements and admixtures," ACI Materials Journal, Vol. 89, No. 2, 1992, pp. $188-196$.

8. Soutsos, M., Hatzitheodorou, A., Kanavaris, F. and Kwasny, J. "Effect of temperature on the strength development of mortar mixes with GGBS and fly ash," Magazine of Concrete Research, Vol. 69, No. 15, 2017, pp. 787-801.

9. Yikici, T. A. and Chen, H.-L. "Use of maturity method to estimate compressive strength of mass concrete", Construction and Building Materials, Vol. 95, 2015, pp. $802-812$

10. Kanavaris, F. "Early age behaviour and cracking risk of concretes containing GGBS”, PhD Thesis, Queen's University of Belfast, UK, 2017.

11. Soutsos, M., Turu'allo, G., Owens, K., Kwasny, J., Barnett, S. J. and Basheer, P. A. M. "Maturity testing of lightweight self-compacting and vibrated concretes," Construction and Building Materials, Vol. 47, 2013, pp. 118-125.

12. Sofi, M., Mendis, P. A. and Baweja, D. "Estimating early-age in situ strength development of concrete slabs", Construction and Building Materials, Vol. 29, 2012, pp. 659-666.

13. Barnett, S. J., Soutsos, M. N., Millard, S. G. and Bungey, J. H. "Strength development of mortars containing ground granulated blast-furnace slag: Effect of curing temperature and determination of apparent activation energies", Cement and Concrete Research, Vol. 36, No. 3, 2006, pp. 434-440. 
14. Verbeck, G. J. and Helmuth, R. H. "Structure and physical properties of cement paste,” Proc. Fifth Int. Symp. On the Chemistry of Cement, Part III, Tokyo, 1968, pp. 1-32.

15. Soutsos, M., Kanavaris, F. and Hatzitheodorou, A. "Critical analysis of strength estimates from maturity functions", Case Studies in Construction Materials, Vol. 9, 2018, e0018, pp. 1-19.

16.

17. Turkel, S. and Alabas, V. "The effect of excessive steam curing on Portland composite cement concrete", Cement and Concrete Research, Vol. 35, No. 2, 2005, pp. 405-411.

18. McIntosh, J. D. "The effects of low-temperature curing on the compressive strength of concrete,” Proc. RILEM Symp. On Winter Concreting, Session BII, Copenhagen, Danish Institute for Building Research, Copenhagen, 1956, p. 17.

19. Copeland, L., E., Kantro, D., L. and Verbeck, G. (1962), "Chemistry of hydration of Portland cement: Energetics of the hydration of Portland cement", In: Proceedings of the 4th International Symposium on Chemistry of Cement, NBS Monograph 453, Washington D.C., pp. 453-462.

20. Gallucci, E., Zhang, X. and Scrivener, K. L. (2013), “Effect of temperature on the microstructure of calcium silicate hydrate (C-S-H)", Cement and Concrete Research, 53, pp. 185-195.

21. Roy, D., M. and Idorn, G., M. (1982), "Hydration, structure and properties of blast furnace slag cements, mortars and concrete”, ACI Journal, pp. 444-457.

22. Ezziane, K., Bougara, A., Kadri, A., Khelafi, H. and Kadri, E. (2007), "Compressive strength of mortar containing natural pozzolan under various temperatures", Cement and Concrete Composites, 29(8), pp. 587-593. 
23. Escalante-Garcia, J., I. and Sharp, J., H. (1998), "Effect of temperature on the hydration of the main clinker phases in Portland cement: Part I, neat cements", Cement and Concrete Research, 28(9), pp. 1245-1257.

24. Escalante-Garcia, J., L. and Sharp, J., H. (2001), "The microstructure and mechanical properties of blended cements hydrated at various temperatures", Cement and Concrete Research, 31(5), pp. 695-702.

25. Chanvillard, G. and D’Aloia, L. “Concrete strength estimation at early ages: modification of the method of equivalent age", ACI Materials Journal, Vol. 94, No. 6, 1997, pp. 520-530.

26. Kjellsen, K.O. and Detwiler, R.J. "Later-age strength prediction by a modified maturity model”, ACI Materials Journal, Vol. 90, No. 3, 1993, pp. 220-227.

27. Schindler, A. "Effect of temperature on hydration of cementitious systems", ACI Materials Journal, Vol. 101, No. 1, 2004, pp. 72-81.

28. Soutsos, M., Hatzitheodorou, A., Kanavaris, F. and Kwasny, J. “Compressive Strength Estimates of Adiabatically Cured Concretes Using Maturity Methods”, Journal of Materials in Civil Engineering, Vol. 31, No. 7, 2019.

29. Kanavaris, F., Soutsos, M., Chen, J-F. and Nanukuttan, S. "An investigation on appropriate curing regimes for precast concrete structural elements with GGBS using maturity functions", International RILEM/COST Conference on Interdisciplinary Approaches for Cement-based Materials and Structures SynerCrete18', (Azenha, M., Schlicke, D., Bendoudjema, F. and Jędrzejewska, A. (eds.)), October 2018, Funchal, Madeira, Portugal.

30. D. Schlicke, F. Kanavaris, R. Lameiras and M. Azenha, “On-site monitoring”, Book chapter in: RILEM State-of-the-art report in cracking mitigation in 
massive concrete structures (Fairbairn, E. and Azenha, M. (eds)), Springer, 2019.

31. Freiesleben Hansen, P., and Pedersen, E.J. "Curing of concrete structures," CEB Inf. Bull., 166, May, 1985.

32. Carino, N. J. "The Maturity Method," in Handbook on Nondestructive Testing of Concrete, Editors: Malhotra, V. M. and Carino, N. J., $2^{\text {nd }}$ Edition, CRC Press, 2004, pp. 5.1- 5.47.

33. Soutsos, M., N. "Effect of temperature on the rate of strength development of mortar mixes", in: 13th International Conference on Structural Faults and Repair - 2010 (Forde, M., C. (ed)), Engineering Technics Press, Edinburgh, UK.

34. Soutsos, M. and Kanavaris, F. "The modified nurse-saul (MNS) maturity function for improved strength estimates at elevated curing temperatures", Case Studies in Construction Materials, Vol. 9, 2018, e00206, p. 14.

35. British Standards Institution, "BS EN 206:2013+A1:2016, Concrete. Specification, performance, production and conformity", BSI, London, UK, 2013.

36. British Standards Institution, "BS EN 197-1:2011 - Cement. Composition, specifications and conformity criteria for common cements", BSI, London, UK, 2011.

37. British Standards Institution, "BS EN 196-1-2005 - Methods of testing cement. Determination of strength”, BSI, London, UK, 2005.

38. British Standards Institution, "BS EN 12620:2002+A1:2008, Aggregates for concrete", BSI, London, UK, 2002. 
39. British Standards Institution, "BS EN 12350-2:2009, Testing fresh concrete. Slump-test”, BSI, London, UK, 2009.

40. British Standards Institution, "BS EN 12390-1:2012, Testing hardened concrete Part 1: Shape, dimensions and other requirements for specimens and moulds", BSI, London, 2012.

41. British Standard Institution, "BS EN 12390-3:2019 Testing hardened concrete. Compressive strength of test specimens", BSI , London, 2019.

42. Barnett, S. J., Soutsos, M. N., Bungey, J. H., and Millard, S. G. "Fast-track construction with slag cement concrete: Adiabatic strength development and strength prediction," ACI Materials Journal, Vol. 104, No. 4, 2007, pp. 388396.

43. Brooks, A.G., Schindler A.K. and Barnes R.W., "Maturity method evaluated for various cementitious materials", J. Mater. Civ. Eng. Vol. 19, Issue 12, 2007, pp. $1017-1025$.

44. J.L. Poole, K.A. Riding, M.C.G. Juenger, K.J. Folliard, A.K. "Schindler Effects of supplementary cementitious materials on apparent activation energy", $J$. ASTM Int., Vol. 7, 2010.

45. J.L. Poole, K.A. Riding, K.J. Folliard, M.C.G. Juenger, A.K. Schindler "Methods for calculating apparent activation energy for Portland cement", $A C I$ Mater. J., Vol. 104, No. 1, 2007, pp. 303-311. 